\title{
LA-UR-97- $=5013$
}

\author{
Title: FORMATION OF A METASTABLE BCC SOLID \\ SOLUTION AND DECOMPOSITION TO A C15 LAVES \\ PHASE IN MELT-SPUN CrNb $\mathrm{CTi}_{10}$

$$
\begin{array}{r}
\text { CONF-971201- } \\
\text { RECEIVED } \\
\text { ARR OS } 1998 \\
\text { OSTI }
\end{array}
$$ \\ Author(s): KATHERINE C. CHEN, MST-6 \\ DAN J. THOMA, MST-6 \\ PAUL G. KOTULA, CMS \\ FUMING CHU, MST-8
}
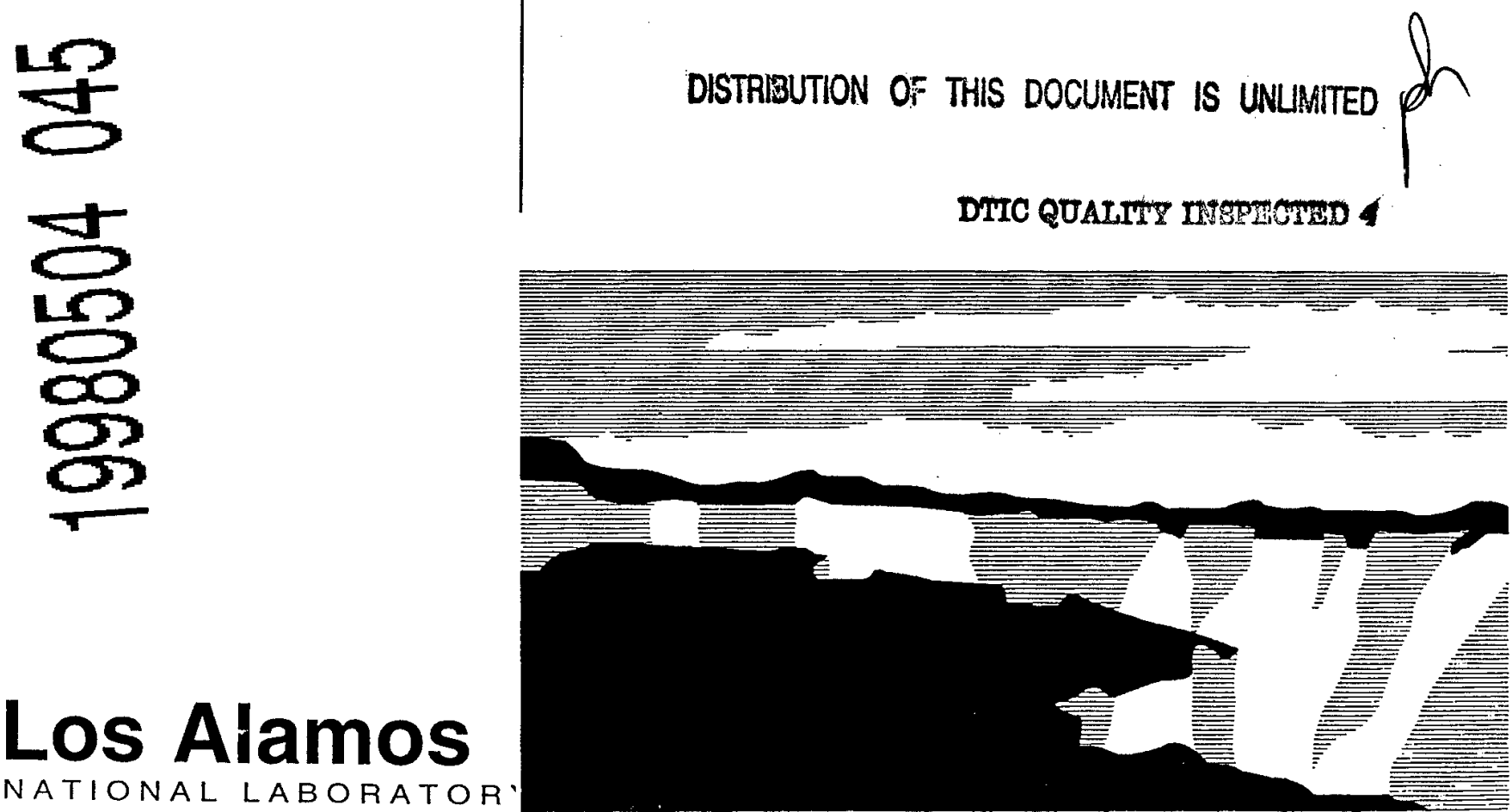

NATIONAL LABORATOR

Los Alamos National Laboratory, an affirmative action/equal opportunity employer, is operated by the University of California for the U.S. Department of Energy under contract W-7405-ENG-36. By acceptance of this article, the publisher recognizes that the U.S. Government retains a nonexclusive, royalty-free license to publish or reproduce the published form of this contribution, or to allow others to do so, for U.S. Government purposes. The Los Alamos National Laboratory requests that the publisher identify this article as work performed under the auspices of the U.S. Department of Energy. 


\section{DISCLAIMER}

This report was prepared as an account of work sponsored by an agency of the United States Government. Neither the United States Government nor any agency thereof, nor any of their employees, makes any warranty, express or implied, or assumes any legal liability or responsibility for the accuracy, completeness, or usefulness of any information, apparatus, product, or process disclosed, or represents that its use would not infringe privately owned rights. Reference herein to any specific commercial product, process, or service by trade name, trademark, manufacturer, or otherwise does not necessarily constitute or imply its endorsement, recommendation, or favoring by the United States Government or any agency thereof. The views and opinions of authors expressed herein do not necessarily state or reflect those of the United States Government or any agency thereof. 


\section{FORMATION OF A METASTABLE BCC SOLID SOLUTION AND DECOMPOSITION TO A C15 LAVES PHASE IN MELT-SPUN CrNb ${ }_{10} \mathrm{Ti}_{10}$}

Katherine C. Chen, Paul G. Kotula, Fuming Chu, and Dan J. Thoma

Materials Science and Technology Division, Mail Stop G755

Los Alamos National Laboratory, Los Alamos, NM 87545, USA

kchen@lanl.gov

\section{ABSTRACT}

A metastable, disordered bcc phase has been formed from the melt in a Cr-rich alloy of the $\mathrm{Nb}-\mathrm{Cr}-\mathrm{Ti}$ system, where large volume fractions of the Laves phase would develop under equilibrium solidification conditions. X-ray diffraction (XRD) studies and lattice constant determinations confirm that the melt-spun ribbons contain a bcc phase beyond its terminal solid solution limits. Solidification pathways are proposed based upon metastable and equilibrium phase diagrams. Microstructures have been studied using optical microscopy, scanning electron microscopy (SEM), and transmission electron microscopy (TEM). Cross-sectional TEM reveals tiny, dispersed Laves phase precipitates within the metastable bcc grains near the chill (wheel) side. Away from the wheel, the microstructure changes to a dendritic structure of the bcc and C15 Laves phase. Annealing of the melt-spun ribbons produces a fine, two-phase microstructure of the equilibrium phases. Microstructures from the melt-spun and arc-melted processing conditions are compared. The microstructural control afforded through this metastable processing route enables a methodology to tailor phase distributions for optimized toughness in Laves phase alloys.

\section{INTRODUCTION}

Rapid solidification techniques offer potential to produce alloys with reduced segregation, very fine grain sizes, and metastable phases. A metastable bcc solid solution has been formed by splat-quenching and mechanical alloying in the $\mathrm{Nb}$-Cr binary system [1], $\mathrm{TiCr}_{2}-\mathrm{NbCr}_{2}$ isoplethal section [2], and $\mathrm{NbCr}_{2}-\mathrm{Ti}$ plethal section [2], where the Laves phase $\left(\mathrm{AB}_{2}\right.$ intermetallic) would develop under equilibrium solidification conditions. The normalized differences between the atomic radii obey Hume-Rothery rules for solid solubility, suggesting that a continuous metastable solid solution in the $\mathrm{Nb}-\mathrm{Cr}-\mathrm{Ti}$ system is possible. This study examines rapidly solidified $\mathrm{CrNb}_{10} \mathrm{Ti}_{10}$ by melt-spinning, and the thermal stability of the metastable product.

The expected phases and phase transitions from the melt-spinning process and subsequent annealing treatment are: Liquid $\rightarrow \beta_{m}(\mathrm{bcc}) \rightarrow \beta_{e q}(\mathrm{bcc})+C 15$ Laves phase (where $m$ stands for metastable and $e q$ is equilibrium). The equilibrium two-phase product is being explored as a dual phase alloy for high-temperature structural applications $[3,4,5]$. The $\mathrm{NbCr}_{2}$ Laves phase has been shown to have several desirable properties such as high melting temperature $\left(\sim 1730^{\circ} \mathrm{C}\right)$, hightemperature strength [6], reasonable oxidation resistance [7,8], and appreciable creep resistance [7]. However, the low-temperature brittleness of Laves phase intermetallics often requires the incorporation of an additional, more ductile phase for practical applications [9]. Several twophase (bcc+Laves) alloys have been explored, and studies suggest that an optimized microstructure contain discrete Laves phases in a fine-grain structure $[2,8,10,11]$. The decomposition of a metastable precursor phase from rapid solidification in this study explores and demonstrates a methodology for achieving such microstructures. 


\section{EXPERIMENTAL PROCEDURES}

The alloy for melt-spinning was initially arc-melted for desired compositional uniformity in the final product. Niobium (99.9\%), chromium (99.99\%), and titanium $(99.99 \%)$ were weighed in the appropriate proportions for three separate ingots weighing approximately 20 grams each. For the arc-melting process, the system was evacuated to $<1 \mathrm{~Pa}$ and back-filled with ultra-high purity argon (99.998\%) three times prior to melting. A titanium getter ingot was melted immediately prior to and adjacent to the melting of the ingot. The ingots were melted and flipped over five times.

After the alloys were arc-melted, they were loaded into a $\mathrm{BN}$ crucible with an orifice diameter of $0.64 \mathrm{~mm}$. The melt-spinning chamber was evacuated to $<1.3 \mathrm{~Pa}$ and back-filled with ultra-high purity helium three times. The operating pressure in the chamber was $\sim 8.4 \times 10^{4} \mathrm{~Pa}$. Using induction heating, the alloy was heated (within five minutes) to the pour temperature of $1800^{\circ} \mathrm{C}$. The crucible was lowered to $\sim 1.5 \mathrm{~cm}$ from a copper wheel $(33 \mathrm{~cm}$ in diameter) that was rotating at $2000 \mathrm{rpm}$. A helium gas pressure of $20.7 \times 10^{3} \mathrm{~Pa}$ ejected the molten alloy through the orifice onto the spinning wheel, and the ribbon pieces were collected at the end of a four foot long tube. For the annealing treatment, the ribbons were wrapped in $\mathrm{Nb}$ foil, annealed in a tube furnace with $\mathrm{Ti}$ getters at $1300^{\circ} \mathrm{C}$ for 72 hours, and cooled to room-temperature at a cooling rate of $1^{\circ} \mathrm{C} / \mathrm{min}$ cool. Chemical analysis of the as-received material revealed impurity levels of 0.21 wt $\%$ oxygen, $0.42 \mathrm{wt} \%$ nitrogen, and $0.33 \mathrm{wt} \%$ boron. The ribbon composition was found to be approximately 78.7 at $\% \mathrm{Cr}-7.0$ at $\% \mathrm{Nb}-10.4 \mathrm{at} \% \mathrm{Ti}$.

For comparisons of melt-spinning to conventional processing, an ingot of the same alloy composition was arc-melted into a 10 gram button. The ingot was then annealed at $1400^{\circ} \mathrm{C}$ for 100 hours, and cooled at a rate of $1^{\circ} \mathrm{C} / \mathrm{min}$.

$\mathrm{X}$-ray diffraction $(\mathrm{XRD})$ using $\mathrm{Cu} \mathrm{K}_{\alpha}$ radiation was performed on pieces of the melt-spun ribbon with the chill-side or air-side towards the X-rays and detector, while a powder sample was used for the arc-melted sample. Lattice constants were determined from a least squares fit. Crosssectional views of the melt-spun ribbons were analyzed by optical microscopy, scanning electron microscopy (SEM), and transmission electron microscopy (TEM). Volume fractions of different phases were determined by image analysis.

\section{RESULTS AND DISCUSSION}

The XRD scan of the as-received, melt-spun ribbon is shown in Figure 1. A structural difference can be seen between the chill-side and air-side of the ribbons. The chill (or wheel) side would have experienced the fastest cooling rate, and displays predominantly a bcc phase. The bcc phase is also highly textured, suggesting a preferred growth direction along the cube axes, $[100]_{\mathrm{bcc}}$. On the other hand, the air-side of the ribbon contains a bcc and $C 15$ phase. The XRD peaks of the bcc phase are shifted towards higher 2 theta values, indicating a smaller lattice constant. Some solute partitioning occurred, as the bcc solid solution becomes Cr-enriched with the appearance of the $C 15$ Laves phase, $(\mathrm{Nb}, \mathrm{Ti}) \mathrm{Cr}_{2}$. No texture of the bcc phase was apparent on the air-side of the ribbon.

The data in Figure 2 displays the equilibrium bcc lattice constants along the $\mathrm{Nb}_{\mathrm{x} / 2} \mathrm{Ti}_{\mathrm{x} / 2} \mathrm{Cr}_{(100-\mathrm{x})}$ plethal section at $950^{\circ} \mathrm{C}$ [12], and those calculated from Vegard's Rule. The bcc lattice constants from the as-received, melt-spun ribbons are also plotted. The bcc lattice constants of the chill and air-sides are outside the ranges for equilibrium. Although the tie lines in the ternary phase diagram do not necessarily occur along the plethal section, other possible tie lines and bcc lattice constants were considered $(2.891-2.895 \AA)$, assuming minimal solubility in the equilibrium $\mathrm{Cr}$-rich bcc solid solution. A super-saturated and metastable bcc phase was thus 
formed by rapid solidification from the melt-spinning process. However, the value calculated from Vegard's Rule was also not achieved, indicating that either fully metastable bcc was not attained and some solute partitioning occurred, or that significant deviations from ideality occurred.

Laves phases are ordered intermetallics in which particular atoms occupy specific lattice sites. The rapid solidification of the alloy melt hinders the ordering process, resulting in the more disordered bcc

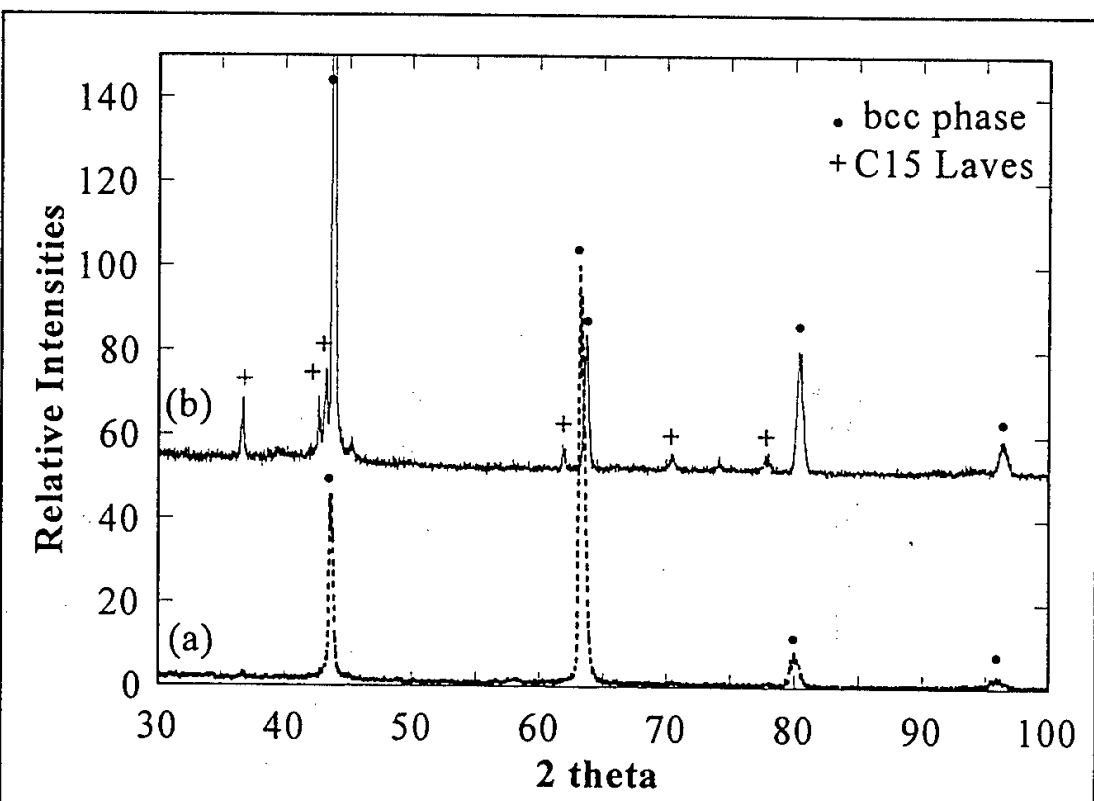

Figure 1. XRD scans from the (a) chill-side and (b) air-side of the as-received, melt-spun ribbon.

phase. Thus, although the Laves phase may be thermodynamically more stable, kinetics prevent their formation in favor of the metastable bcc phase.

The structural differences between the chill and air-sides that were demonstrated with the $\mathrm{XRD}$ analyses, are also apparent from microstructural analyses. A SEM cross-sectional view of an etched melt-spun ribbon is presented in Figure 3. The chill-side contains columnar grains of the metastable bcc phase, which is consistent with the textured XRD scans showing a preferred growth direction. TEM (Figure 4) reveals small amounts of the Laves phase along the grain boundaries and within the grains as tiny particles. Electron diffraction patterns displayed diffuse spots corresponding to the metastable bcc phase, and sharp rings corresponding to the numerous, tiny $C 15$ particles.

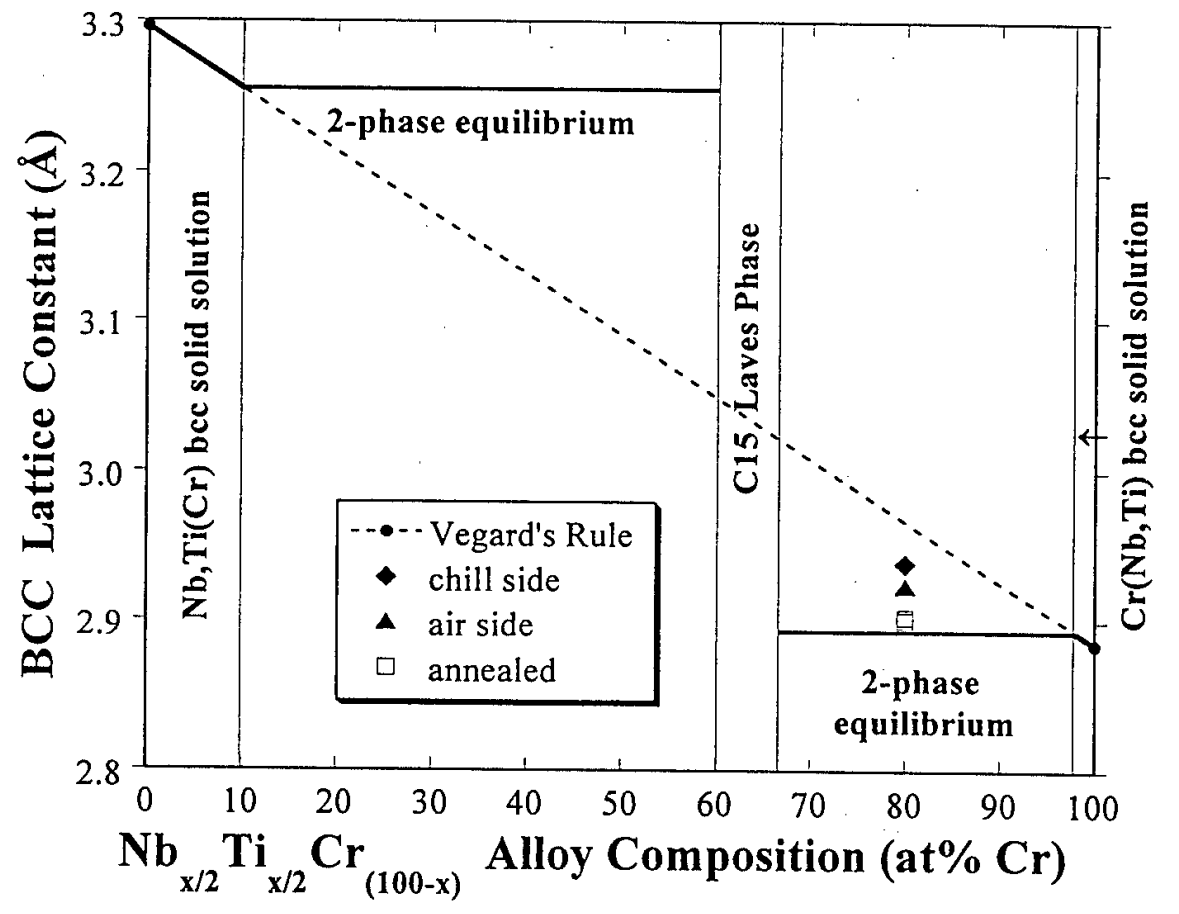

Figure 2. The bcc solid solution lattice constants in equilibrium (bold lines), and by Vegard's Rule (dashed line) as a function of the alloy composition. The bcc lattice constants of the as-received melt-spun ribbons fall outside the equilibrium bcc ranges. Thus, a supersaturated and metastable bcc phase has formed in the melt-spun ribbons. 


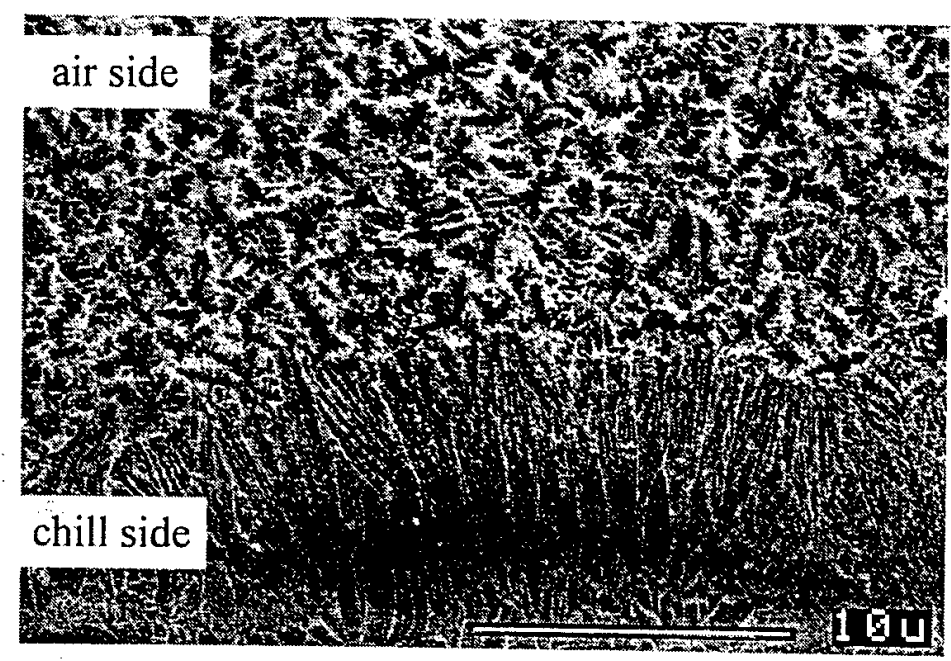

Figure 3. Cross-section SEM of the as-received ribbon.

Further away from the wheel, more and larger Laves particles emerge. The air-side of the melt-spun ribbon displays a coarser microstructure of dendritic bcc and $C 15$. An orientation relationship between the two phases was found to be:

$$
\begin{aligned}
& (101)_{\mathrm{bcc}} \|(111)_{C 15} \\
& {[11 \overline{1}]_{\mathrm{bcc}} \|[11 \overline{2}]_{C 15}} \\
& {[\overline{1} 1]_{\mathrm{bcc}} \|[\overline{1} 10]_{C 15}}
\end{aligned}
$$

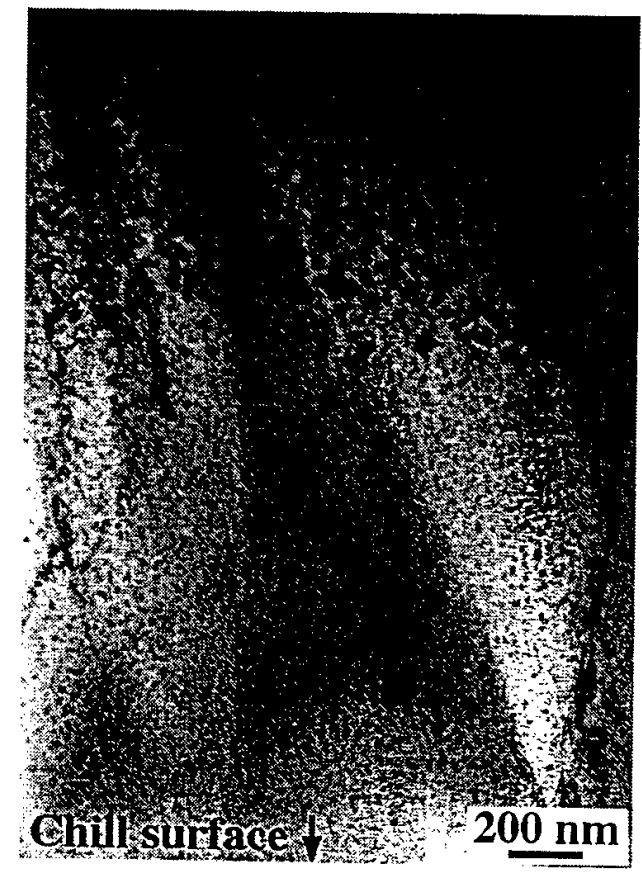

Figure 4. TEM of the chill-side of the melt-spun ribbon. The Laves phase particles become more abundant and larger towards the air-side.

This orientation relationship has also been observed in the $\mathrm{Nb}-\mathrm{NbCr}_{2}$ system [13].

A proposed solidification path is shown in the schematic diagram in Figure 5. The metastable extensions of the bcc liquidus and solidus (dashed lines) across the plethal section is based upon ternary phase diagrams [12]. From the Cr-rich eutectic binary composition, a minimum of about $0.04 \mathrm{~T}_{\mathrm{m}}$ is required to reach $\mathrm{T}_{0}$ (bcc-liquid, dotted line), and to promote the extended bcc solid solution from the liquid. The initial melt was thus undercooled to some unknown temperature below $\mathrm{T}_{0}$ (line 1). Upon recalescence, the initial solid formation may have approached partitionless freezing (vertical line 2), before partitioning of the solute (line 3). The presence of the Laves phase on the air-side of the ribbon suggests the liquid undercooling was

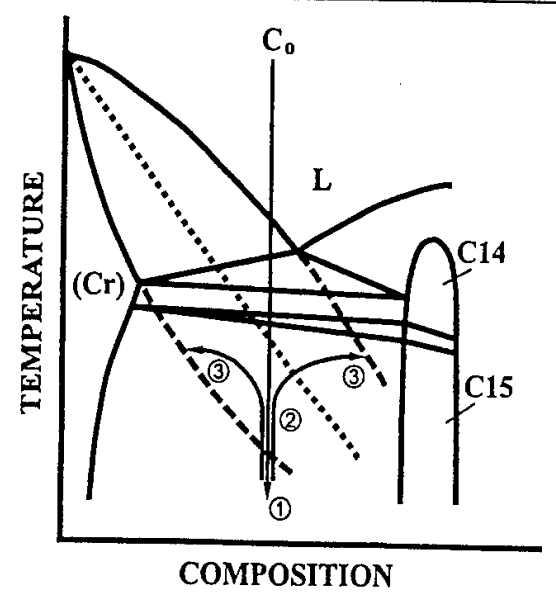

Figure 5. Proposed solidification pathway along the $\mathrm{Cr}_{(100-x)} \mathrm{Nb}_{x / 2} \mathrm{Ti}_{x / 2}$ plethal section. exhausted and that recalescence and solute partitioning was directed out towards the air-side.

Upon annealing, the metastable bcc phase decomposes into the equilibrium bcc and $C 15$ Laves phase. XRD of the annealed ribbon (Figure 6b) shows well-defined peaks from the bcc and $C 15$ phase, as well as peaks from an additional undefined phase (possibly an intermediate phase or impurity). The bcc lattice constant also decreases from the as-received melt-spun condition value. As a result of decomposition, the bcc solid solution becomes more Cr-rich and more $C 15$ phase is produced. The annealed, arc-melted sample (Figure 6c) contains the bcc and $C 15$ phases with similar lattice constants as the annealed ribbon. 


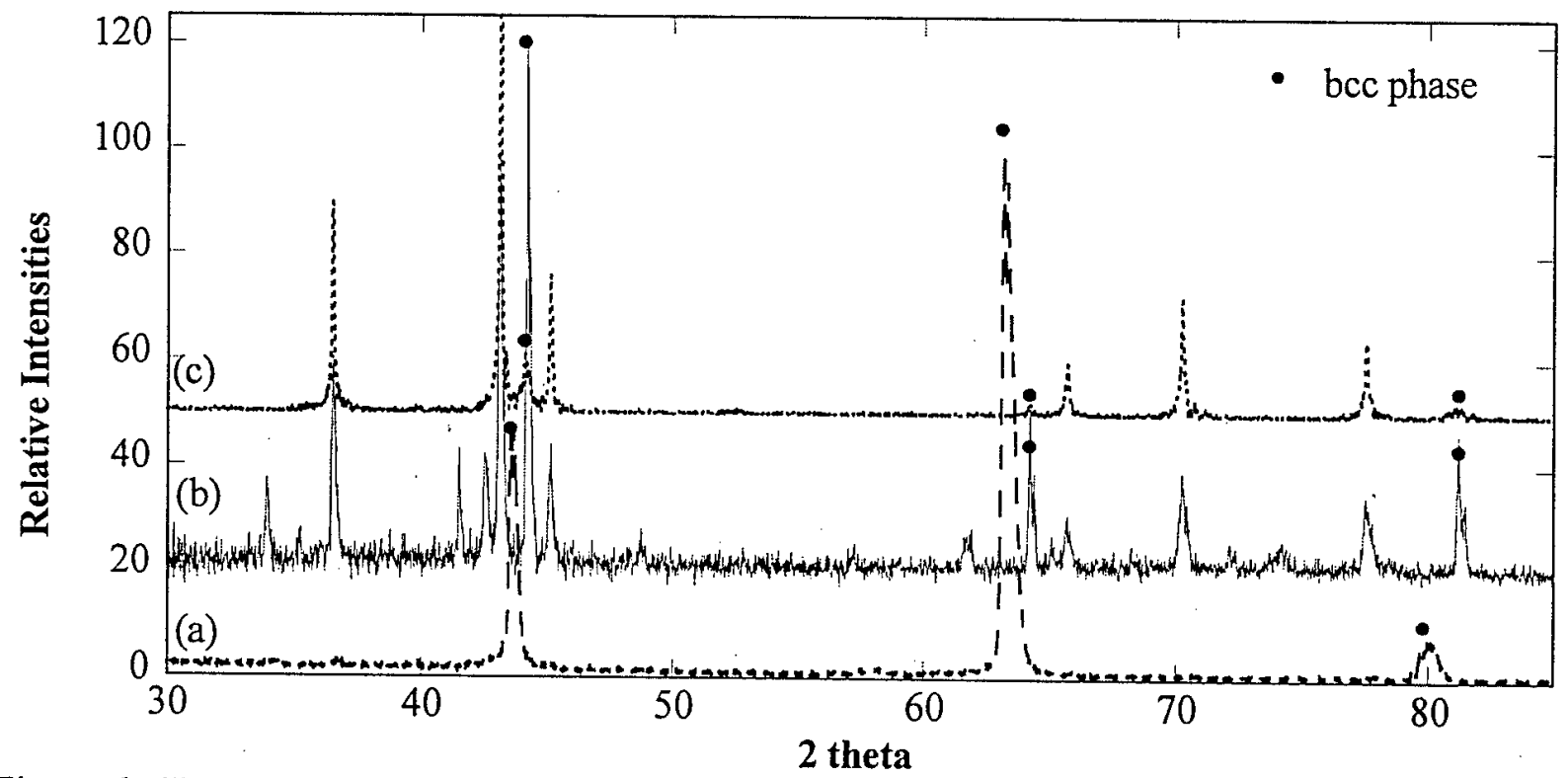

Figure 6. XRD scans of $\mathrm{CrNb}_{10} \mathrm{Ti}_{10}$ : (a) chill-side of as-received, melt-spun ribbon, (b) air-side of the annealed ribbon, and (c) arc-melted and annealed sample.

The decomposed microstructure of the annealed ribbons (Figure 7a) consists of very fine phase distributions (on the order of microns) of the bcc and C15 Laves phase. The Laves phase (lighter contrast) is uniformly dispersed and is roughly 45 volume percent of the alloy. Figure $7 \mathrm{~b}$ represents the microstructure from conventional processing techniques, with about 53 volume percent of the Laves phase. The microstructure of the arc-melted sample is much coarser and shows primary $\mathrm{Cr}$-rich dendrites. Different initial alloy compositions may account for the different volume fractions, but the very different microstructures of the same two phases are produced by the different processing methods.

The decomposition of a metastable precursor bcc phase produced by rapid solidification contrasts with other in situ multiphase microstructure formation techniques (such as directional solidification or precipitation) in that the volume fractions of the phases can be designed to specific amounts and distributions. High-strength and adequate toughness in multiphase intermetallic alloys may be achieved through a uniform, refined microstructure. Thus, rapid solidification and decomposition of a metastable precursor is an effective microstructural tailoring scheme to produce controlled multiphase microstructures.

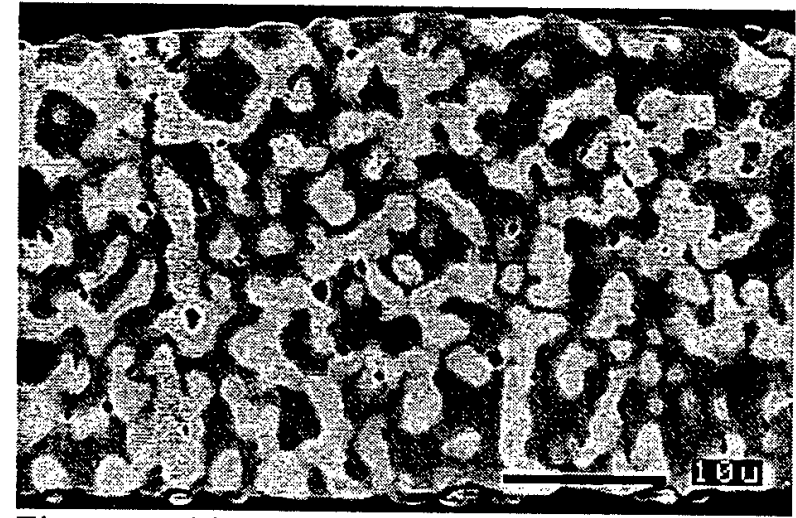

Figure 7(a). Cross-section SEM of the annealed ribbon, showing decomposition into the equilibrium $b c c+C 15$ phases.

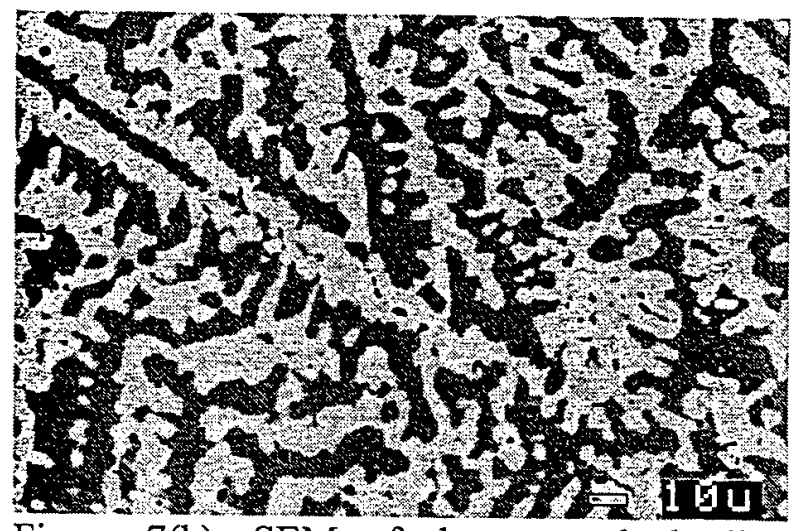

Figure 7(b). SEM of the arc-melted alloy annealed at $1400^{\circ} \mathrm{C}$. A dendritic and coarse microstructure remain. 


\section{CONCLUSIONS}

1. Metastable bcc was achieved in a $\mathrm{CrNb}_{10} \mathrm{Ti}_{10}$ alloy via rapid solidification by a melt-spinning process. The bcc lattice constants $(2.939-2.926 \AA)$ were outside the ranges for the equilibrium bcc phases in the Nb-Cr-Ti system.

2. XRD, SEM, and TEM revealed that the chill-side of the melt-spun ribbons contained columnar grains of the metastable bcc phase. Small amounts of the $C 15$ Laves phase appeared along the bcc grain boundaries and as tiny, dispersed particles within the grains. The air-side of the as-received, melt-spun ribbons had a dendritic microstructure.

3. Decomposition of the metastable bcc phase occurred during annealing at $1300^{\circ} \mathrm{C}$. A fine twophase microstructure (micron length scales) of the equilibrium bcc phase and $C 15$ phase resulted.

4. The alloy composition processed with the conventional arc-melting method, followed by annealing, resulted in a coarse microstructure with remnants of a dendritic structure.

5. Using a metastable precursor which then decomposes into the equilibrium phases offers microstructural control and phase distributions not possible in conventional processing methods. Such a technique allows the optimization of the microstructure and properties of Laves phase intermetallic alloys.

\section{ACKNOWLEDGMENTS}

The authors would like to acknowledge previous research funded through Prof. John $\mathrm{H}$. Perepezko at the University of Wisconsin ARPA (ARO-DAAL-03-90-G-0183). PGK acknowledges a Director-funded postdoctoral fellowship from LANL. This work was supported by the DOE-OBES, Division of Materials Sciences and the Laboratory-Directed Research and Development (LDRD) fund from LANL.

\section{REFERENCES}

1. D.J. Thoma, J.H. Perepezko, D.H. Plantz, and R.B. Schwarz, Mater. Sci. and Eng. A179/A180, 176 (1994).

2. D.J. Thoma and J.H. Perepezko, Materials Science Forum, Vols. 179-181, (1995), pp. 769774.

3. D.J. Thoma and J.H. Perepezko, Mater. Sci. and Eng., A156, 97 (1992).

4. C.T. Liu, P.F. Tortorelli, J.A. Horton, and C.A. Carmichael, Mater. Sci., and Eng., A214, 23 (1996).

5. T. Takasugi, S. Hanada, and K. Miyamoto, J. Mater. Res., 8, 3069 (1993).

6. R.L. Fleischer, MRS Symp. Proc., 133, 305 (1989).

7. D.L. Anton and D.M. Shah, MRS Symp. Proc., 213, 733 (1991).

8. H.J. Goldschmidt and J.A. Brand, J. Less-Common Met., 3, 44 (1961).

9. J.D. Livingston, phys. stat. sol. (a), 131, 415 (1992).

10. K.C. Chen, S.M. Allen, and J.D. Livingston, to be published in Mater. Sci. and Eng.

11. D.L. Davidson, K.S. Chan, and D.L. Anton, Metall. and Mater. Trans., 27A, 3007 (1996).

12. D.J. Thoma, Ph.D. Thesis, University of Wisconsin-Madison, 1992.

13. P.G. Kotula, K.C. Chen, D.J. Thoma, F. Chu, and T.E. Mitchell, Proceedings of Microscopy and Microanalysis 97, edited by G.W. Bailey, R.V.W. Dimlich, K.B. Alexander, J.J. McCarthy, and T.P. Pretlow, (Springer, 1997) p.707. 


\section{INTRODUCTION}

Laves phase intermetallics $\left(\mathrm{AB}_{2}\right)$ are currently being investigated as new, hightemperature structural materials. The $\mathrm{NbCr}_{2}$ Laves phase has been shown to have several desirable properties, such as high-melting temperature $\left(\sim 1730^{\circ} \mathrm{C}\right)$, high-temperature strength, reasonable oxidation, and appreciable creep resistance. However, the lowtemperature brittleness of Laves phase intermetallics often requires the incorporation of an additional, more ductile phase for practical applications. Several two-phase (bcc+Laves) alloys have been explored, and studies suggest that an optimized microstructure contain discrete Laves phases in a fine-grain structure. In this study, the decomposition of a metastable precursor phase from rapid solidification demonstrates a methodology for achieving such microstructures.

Metastable, disordered bcc phase is formed by melt-spinning, where large volumes of the Laves phase would develop under equilibrium conditions. Annealing the melt-spun ribbons reveals a fine, two-phase structure. Microstructures and solidification pathways are examined and compared against the conventional arc-melting process. 


\section{Melt Spinning}

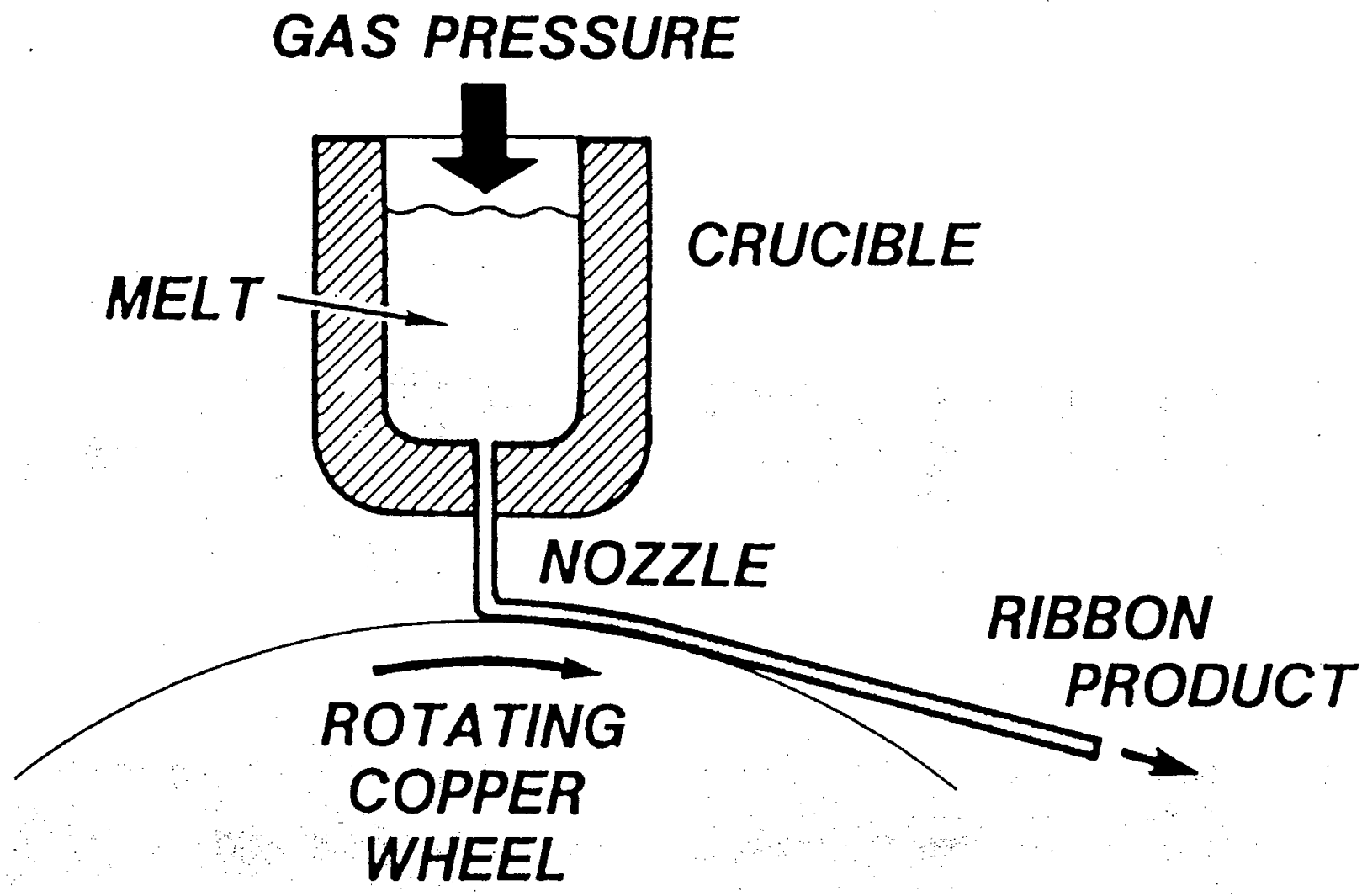

Rapid Solidification Process:

* Compositional homogeneity

* Fine grain sizes

* Metastable phases 


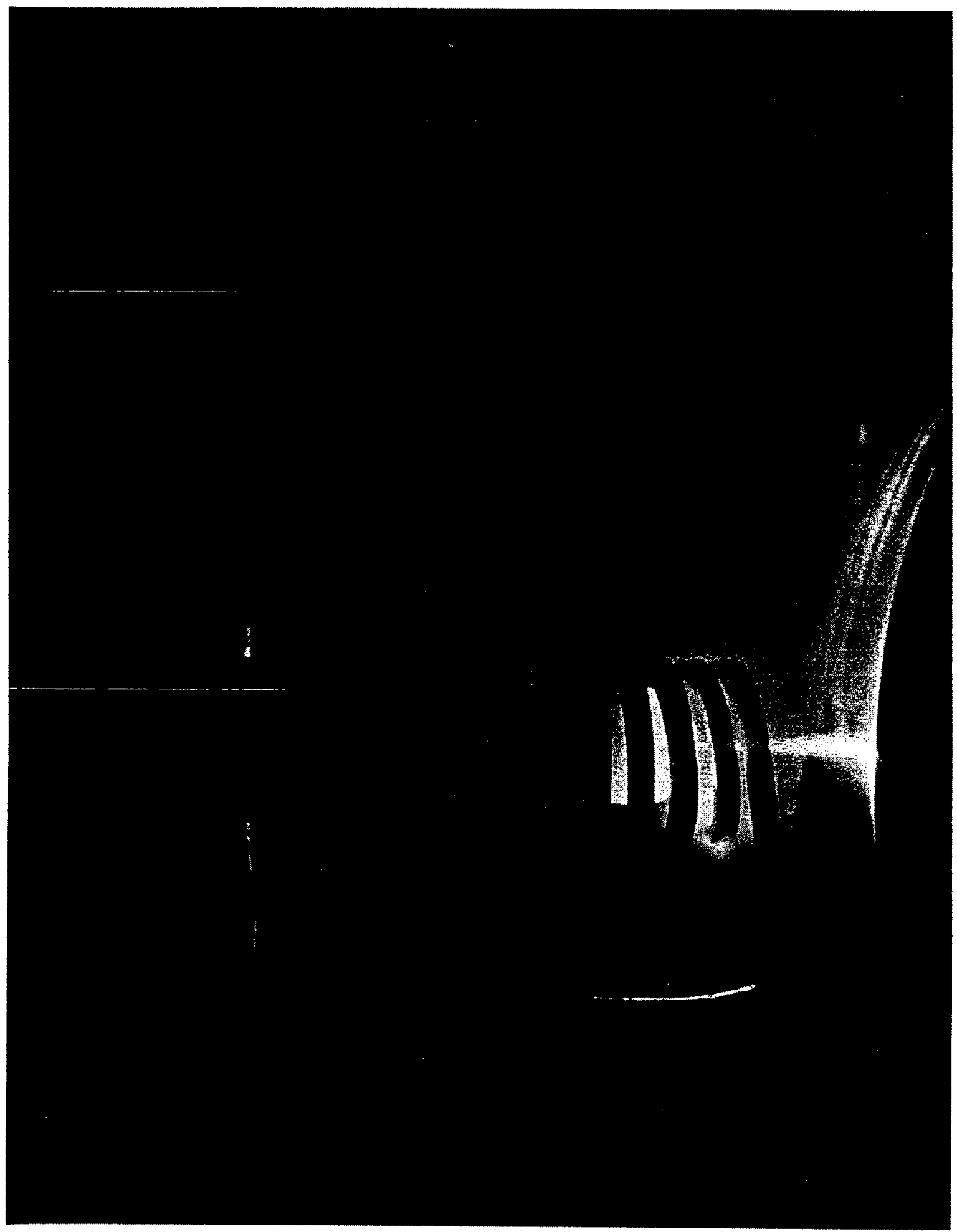




\section{The Equilibrium Cr-Nb-Ti Phase Diagram}

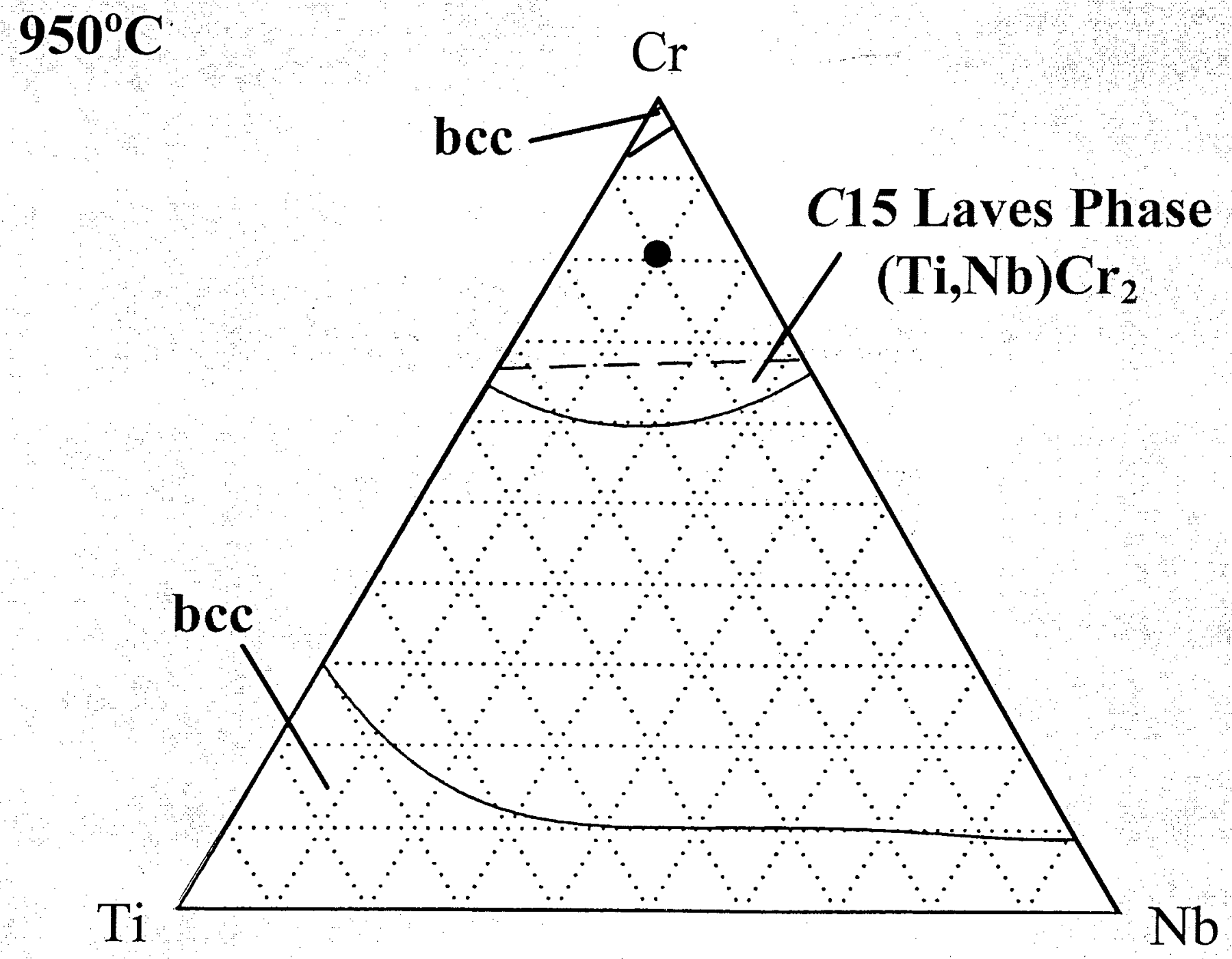




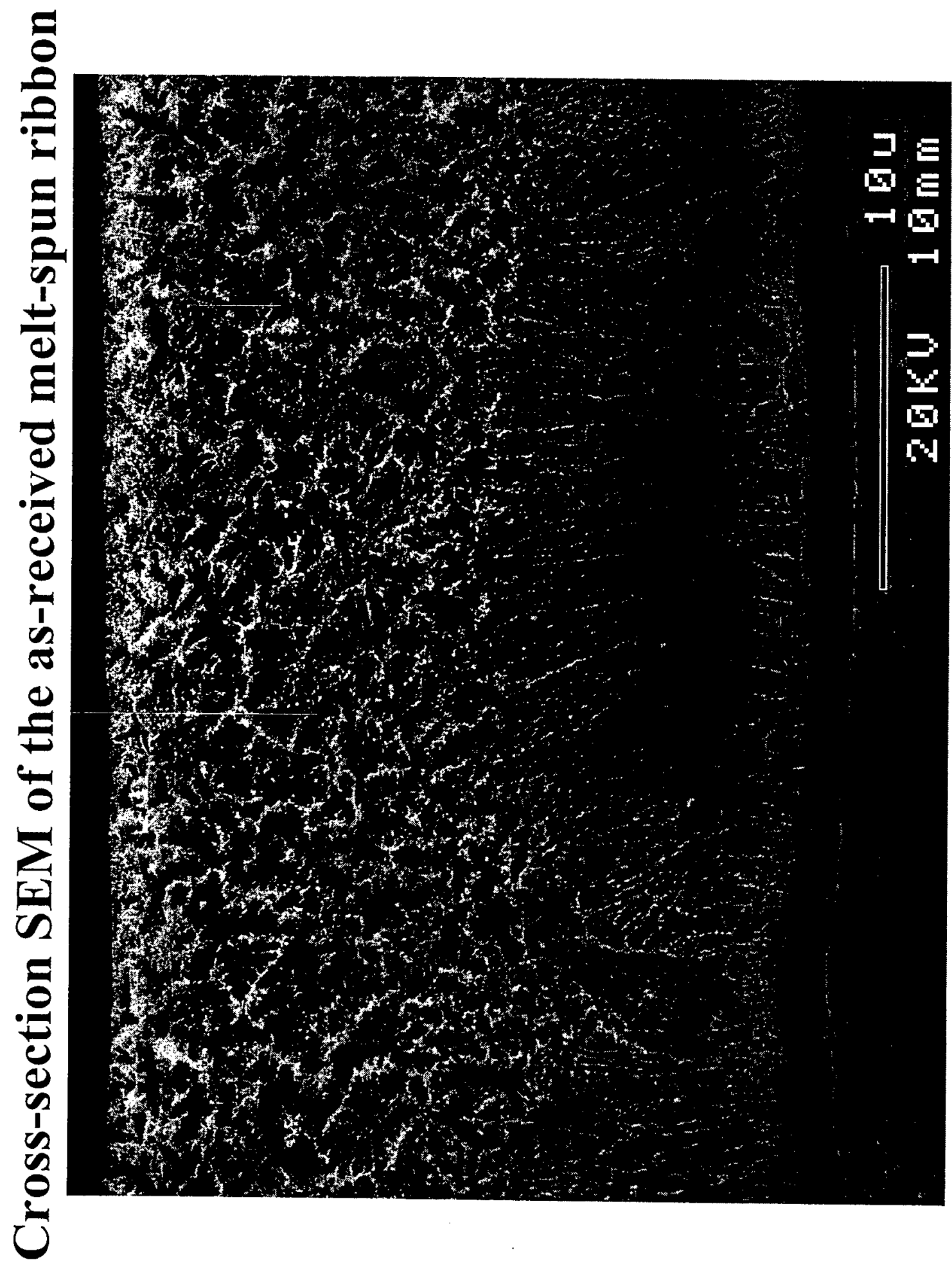




\section{As-Received $\mathrm{CrNb}_{10} \mathrm{Ti}_{10}$ Melt-Spun Ribbons}

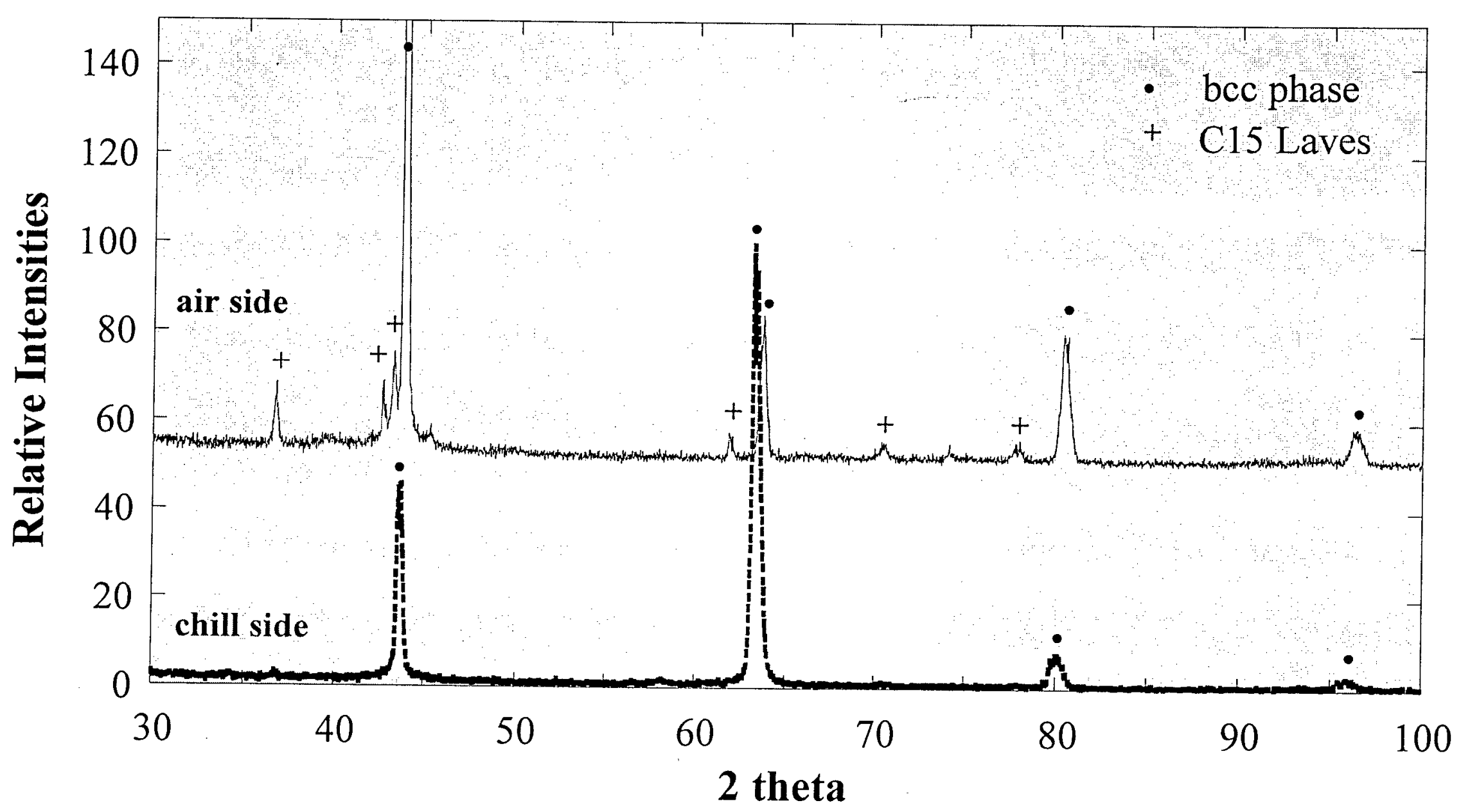

The chill side of the melt-spun ribbon experienced extremely high cooling rates, and therefore retained a metastable bcc phase (textured), while the air-side shows a bcc $+C 15$ structure. 


\section{Phase Equilibrium, BCC Lattice Constants, and Vegard's Rule}

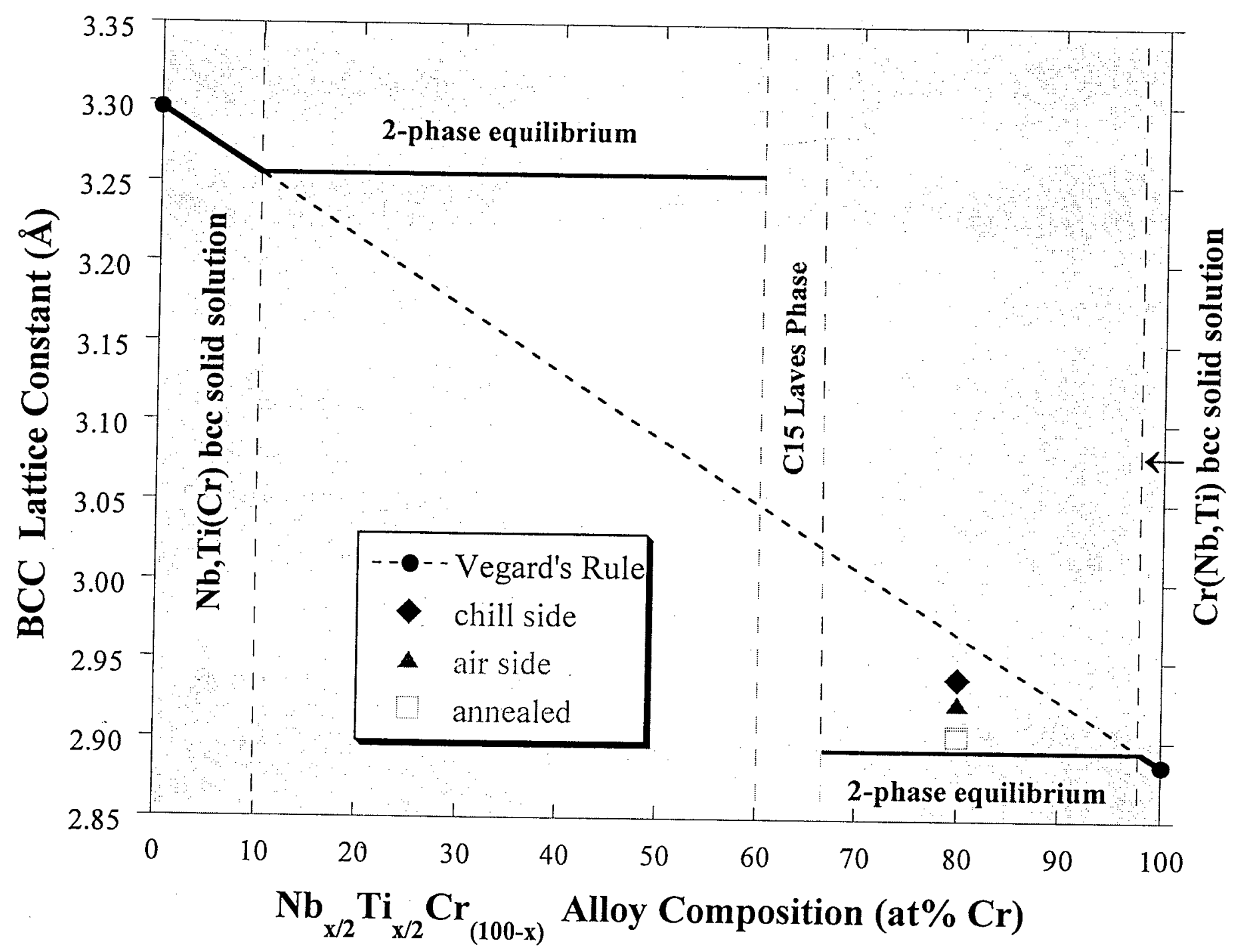

The bcc lattice constants of the as-received, melt-spun ribbons fall outside of the equilibrium solubility limits, suggesting that the bcc phase is supersaturated and metastable. 


\section{Solidification Pathway}

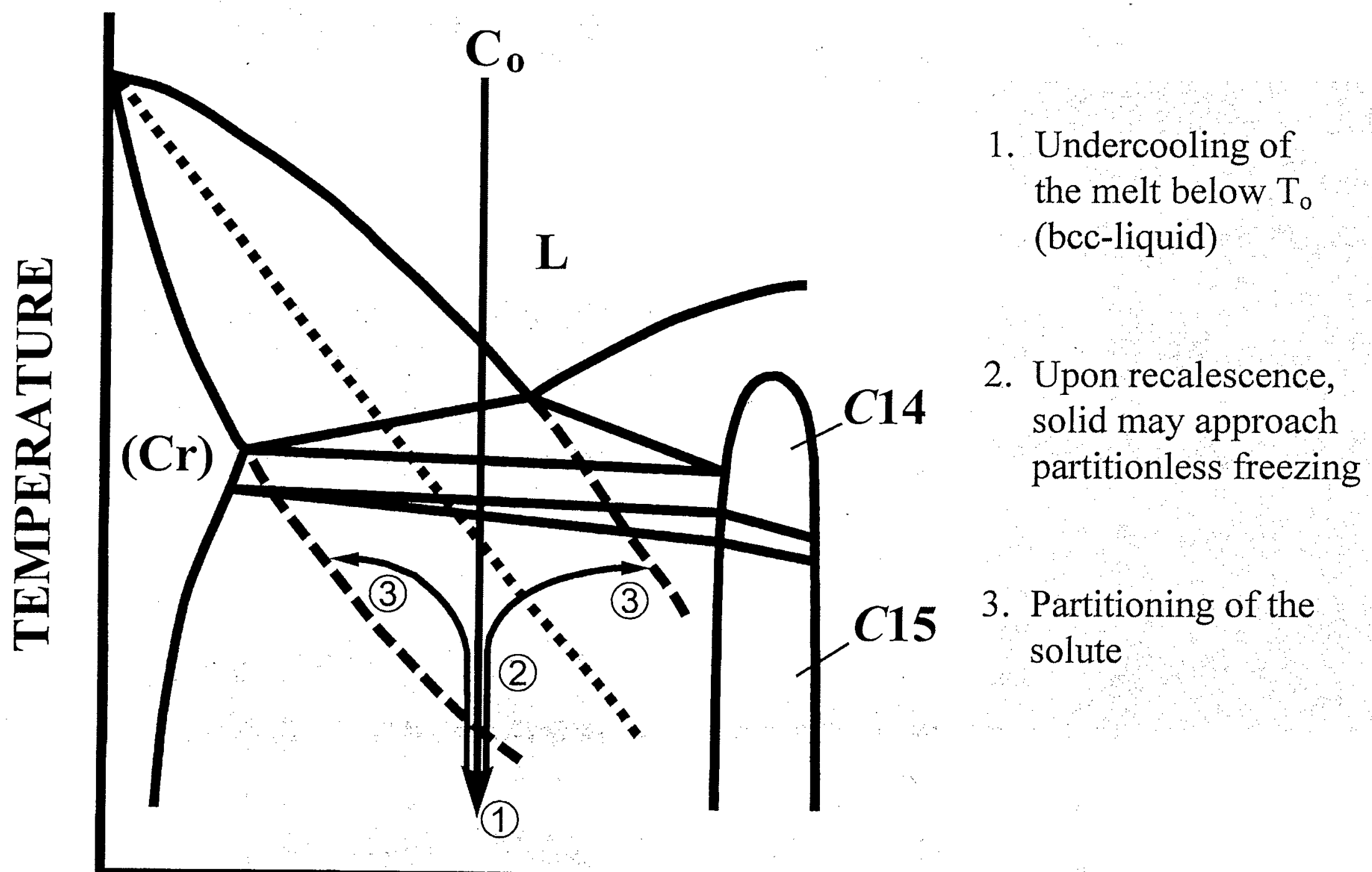

COMPOSITION: $\mathrm{Cr}_{(100-\mathrm{x})} \mathrm{Nb}_{\mathrm{x} / 2} \mathrm{Ti}_{\mathrm{x} / 2}$ 


\section{Microstructures of the As-Received $\mathrm{CrNb}_{10} \mathrm{Ti}_{10}$ Melt-Spun Ribbons}

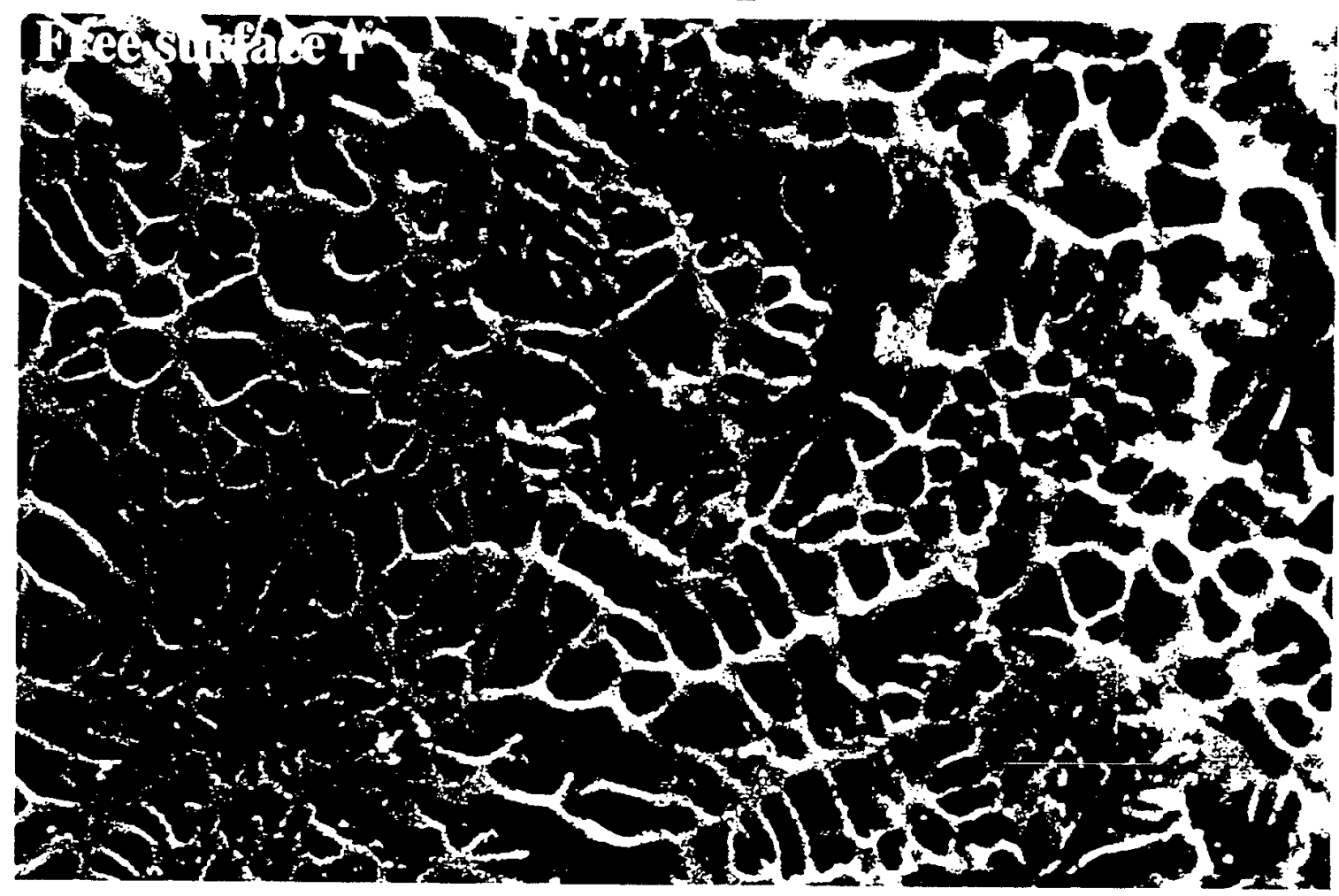

SEM Secondary electron image

Free surface

bec $\mathrm{C} 15$

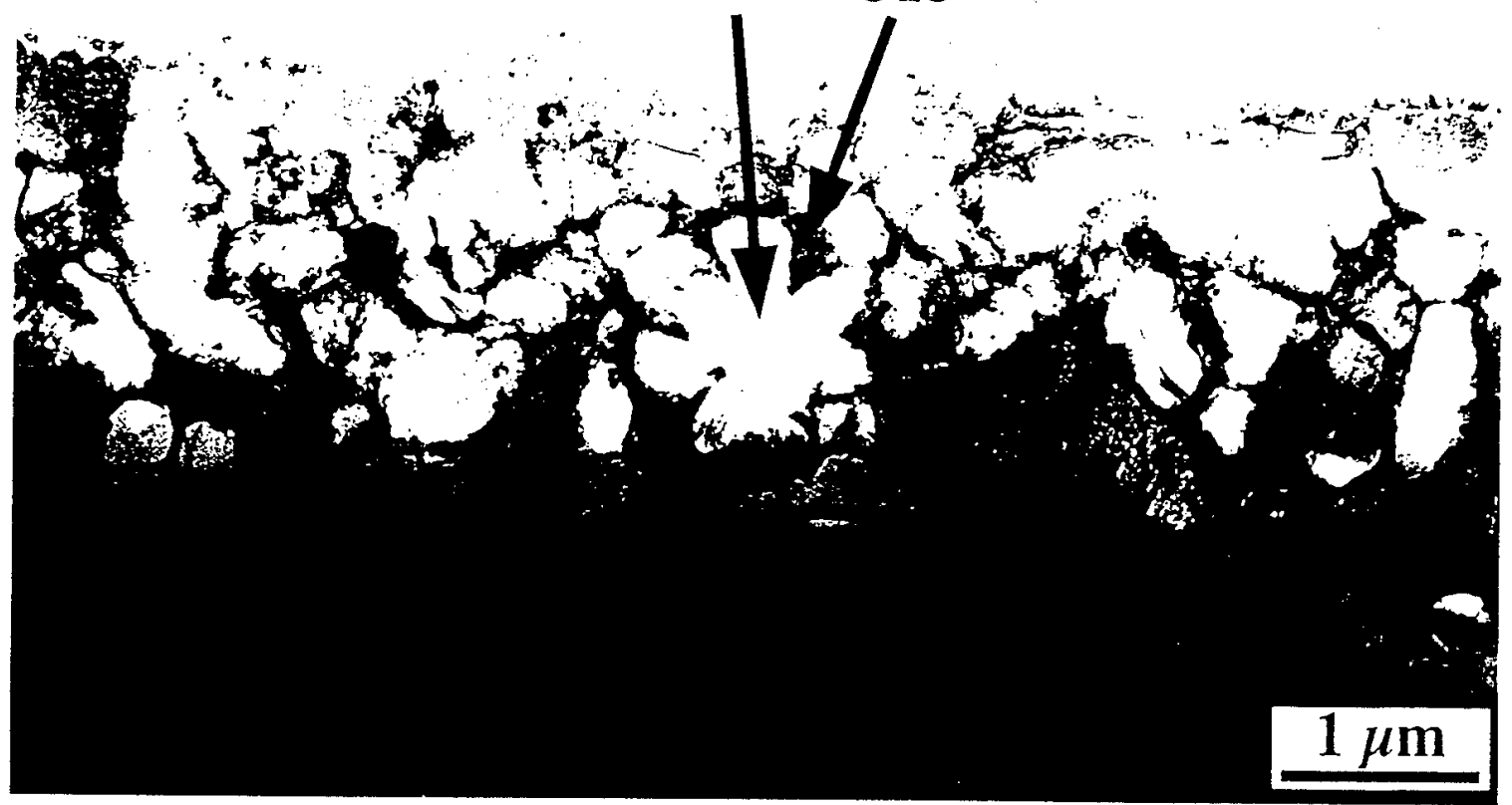

TEM Bright-field image 


\section{Microstructures of the As-Received $\mathrm{CrNb}_{10} \mathrm{Ti}_{10}$ Melt-Spun Ribbons}

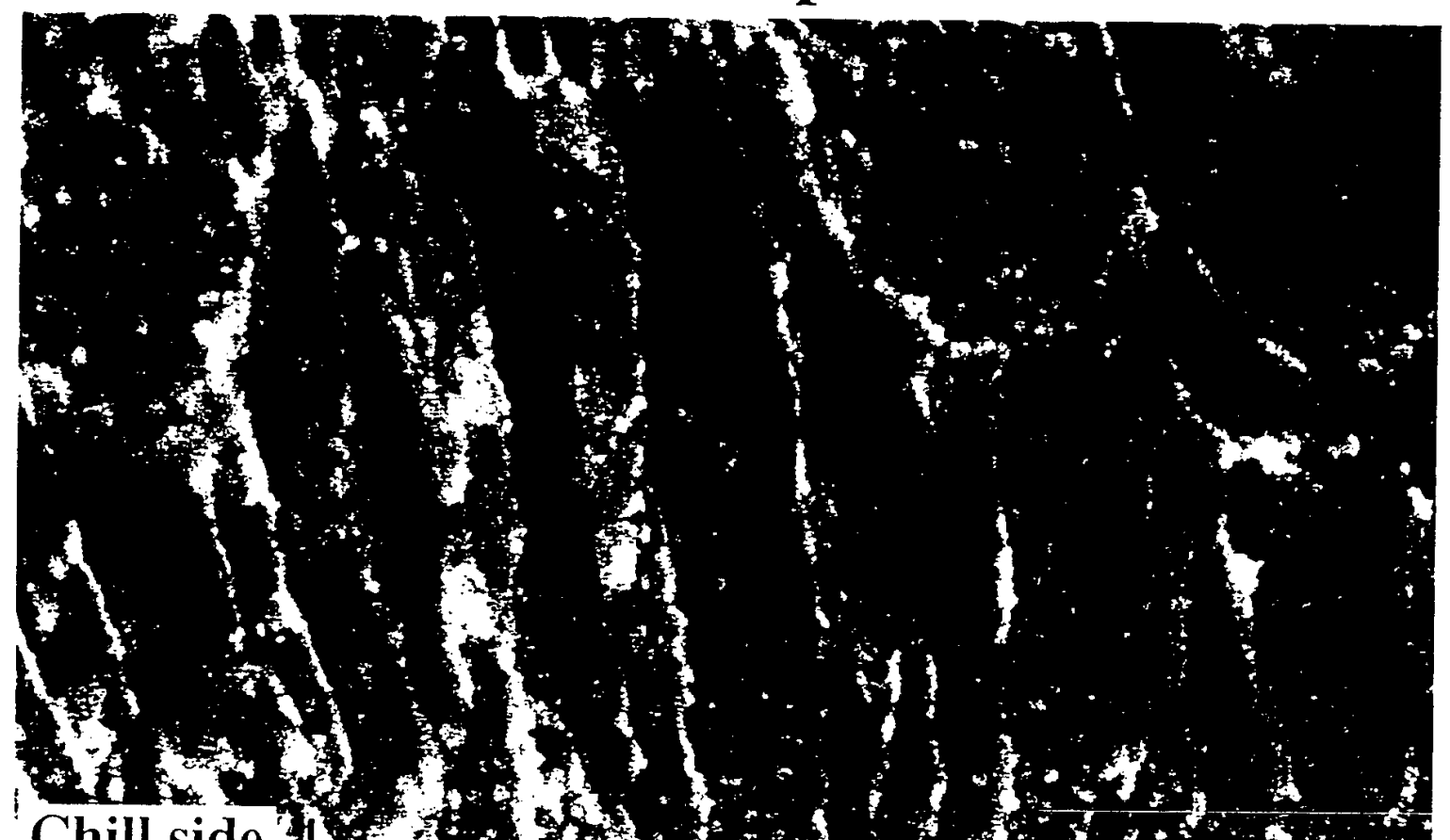

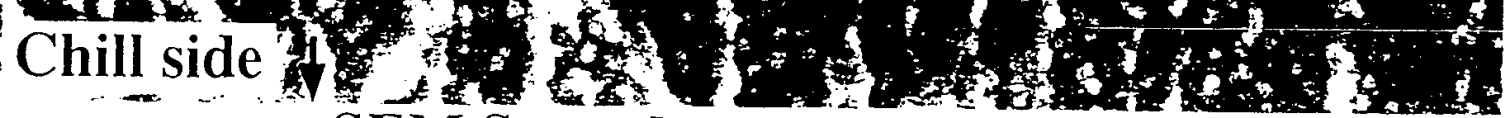
SEM Secondary electron image

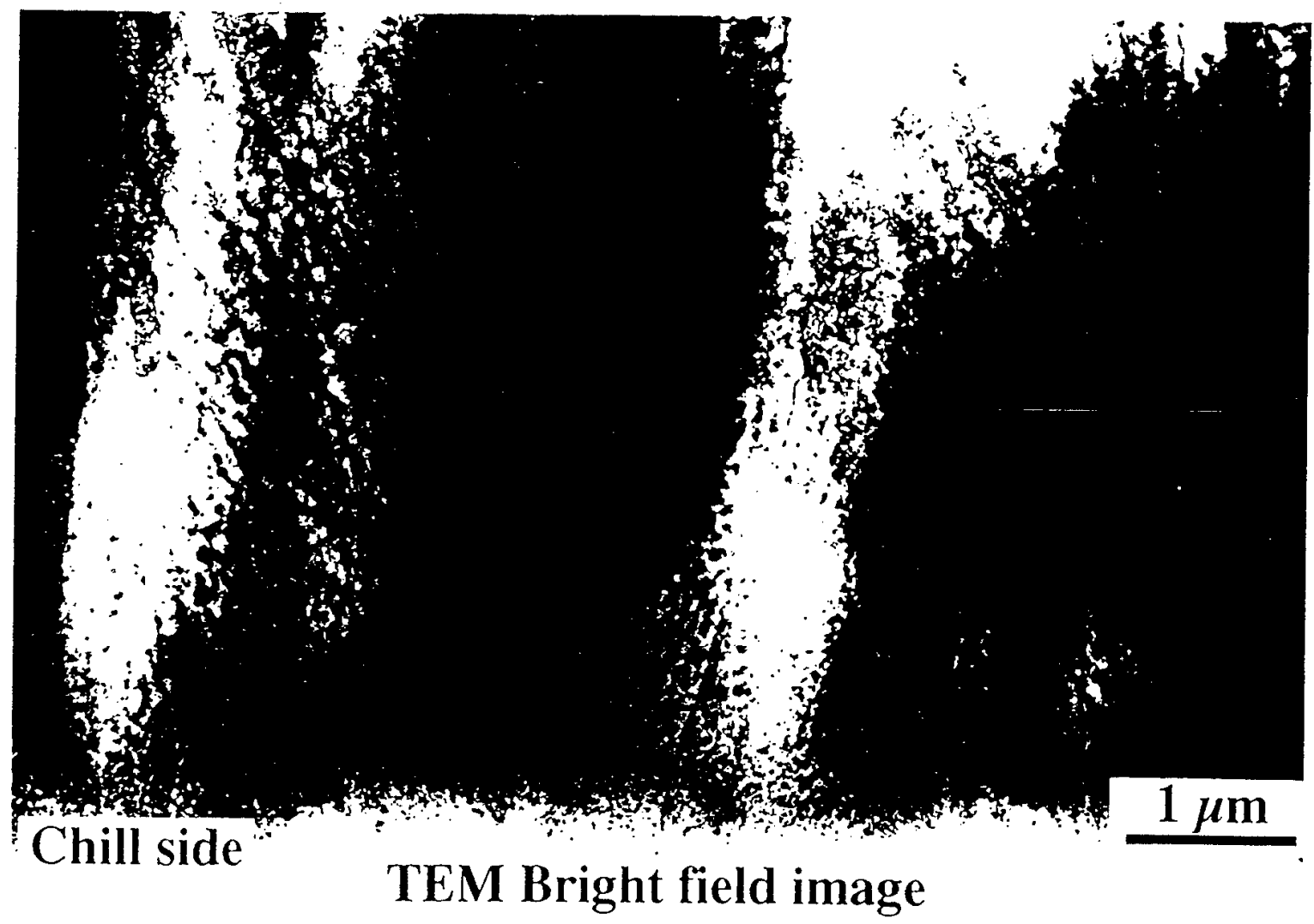




\section{Microstructures of the As-Received $\mathrm{CrNb}_{10} \mathrm{Ti}_{10}$ Melt-Spun Ribbons}

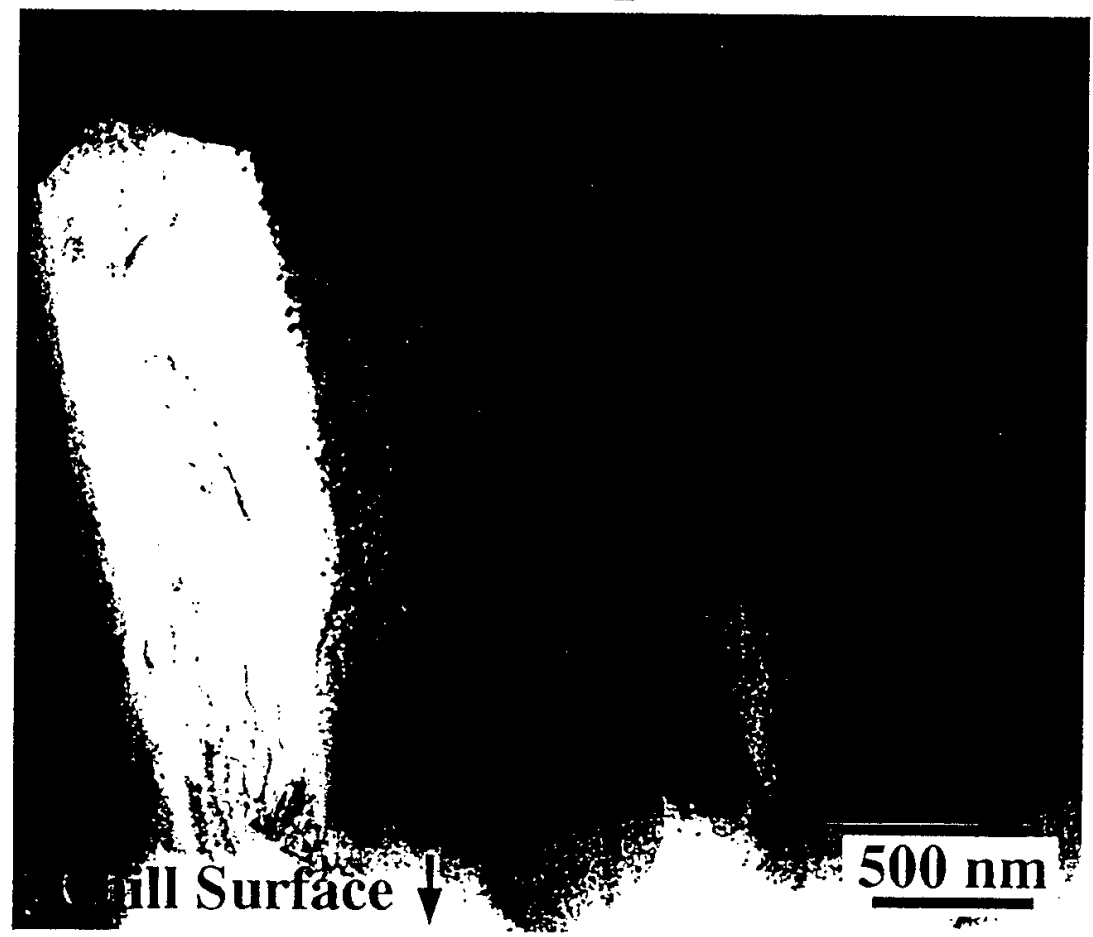

TEM Bright field image

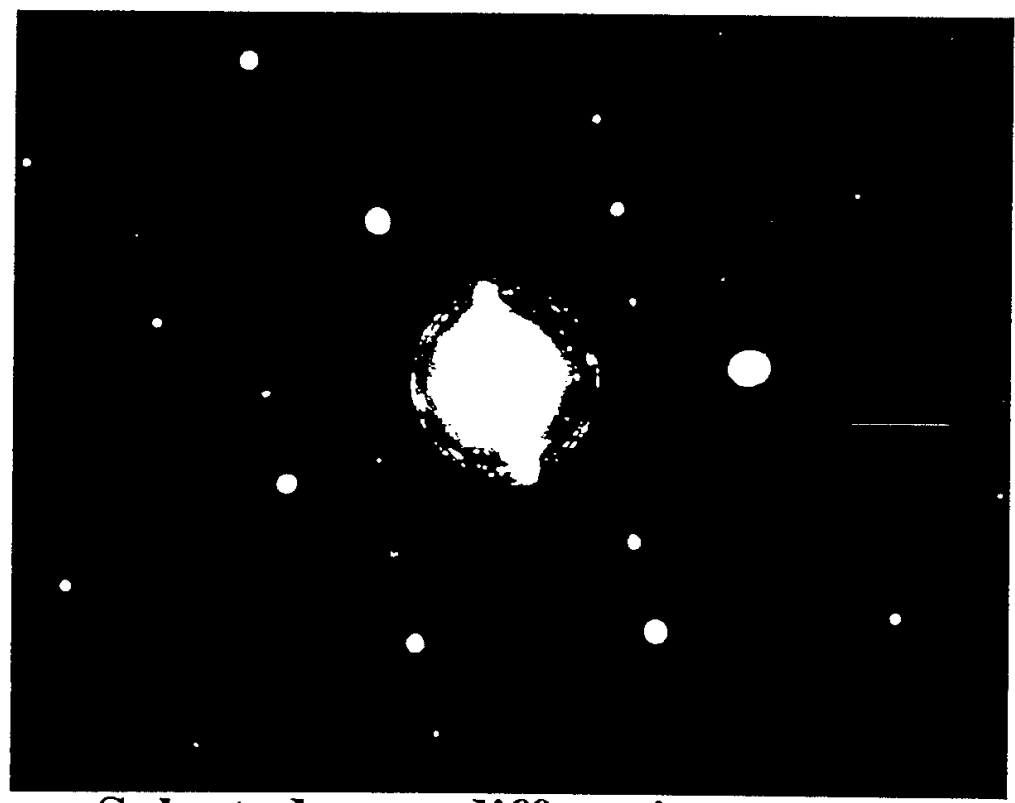

Selected-area diffraction pattern Metastable bcc (diffuse reflections)

C15 (sharp rings) 


\section{BCC-C15 Orientation relationship at the free surface}

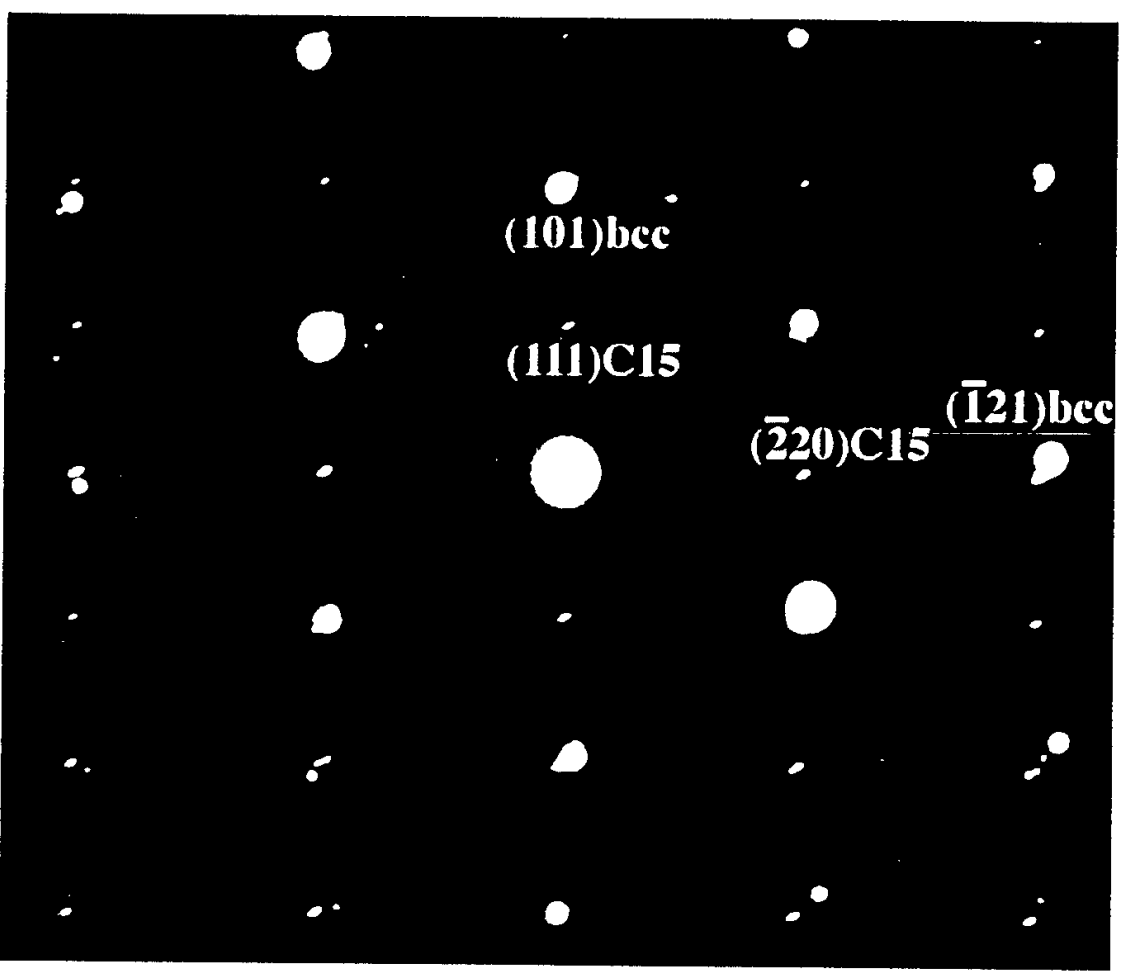

$[11 \overline{1}] \mathrm{bcc},[11 \overline{2}] \mathrm{C} 15$

Similar to that found previously for $\mathrm{Nb}-\mathrm{NbCr}_{2}$ and $\mathrm{Ti}(\mathrm{Cr})-\mathrm{TiCr}_{2}$ 


\section{Cross-Section SEM of the Annealed Melt-Spun Ribbon}

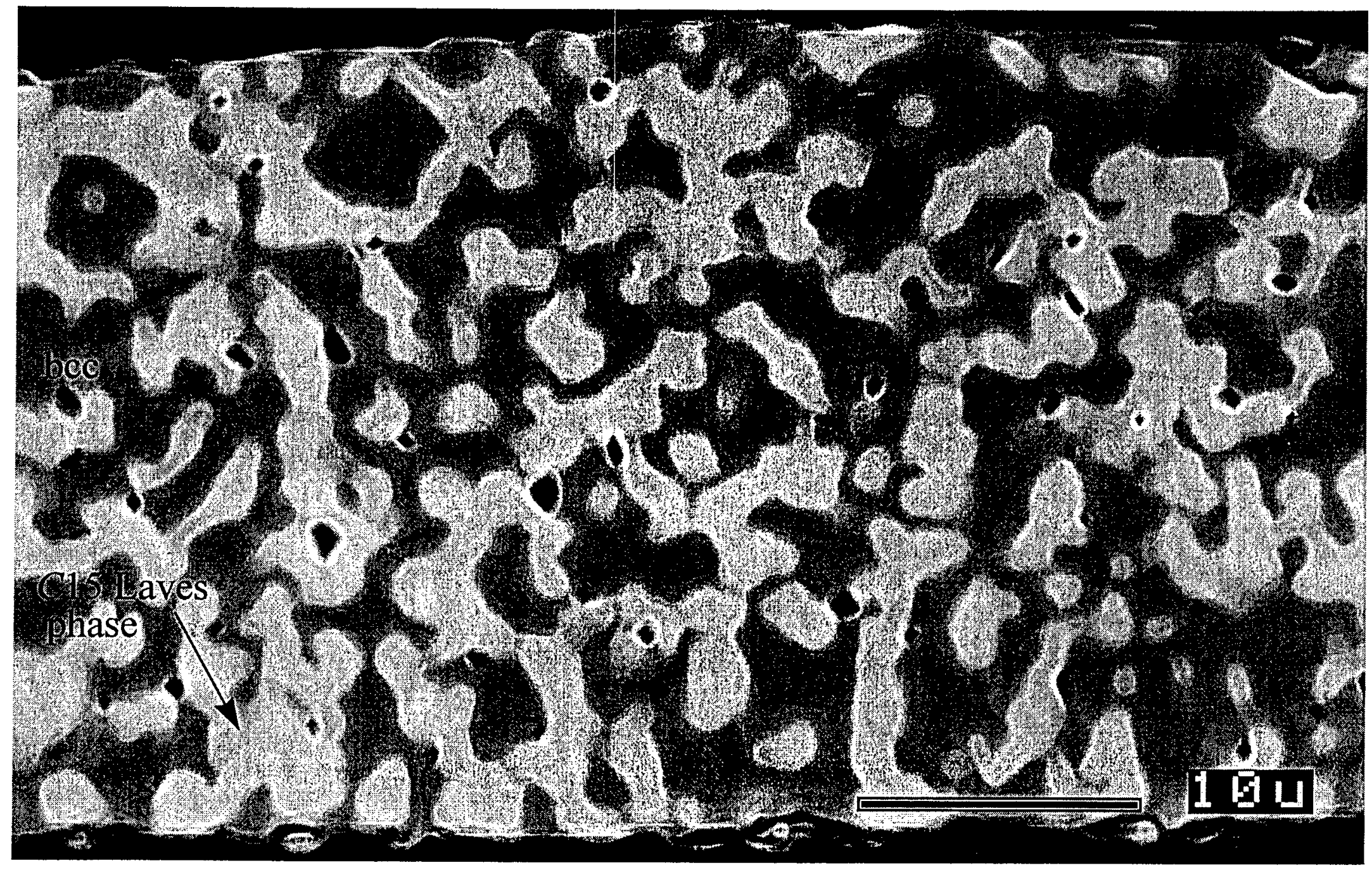

Upon annealing, decomposition of the metastable bcc phase produces a fine phase distribution of the equilibrium bcc and $C 15$ phases. 


\section{Annealed Melt-Spun and Arc-Melted $\mathrm{CrNb}_{10} \mathrm{Ti}_{10}$}

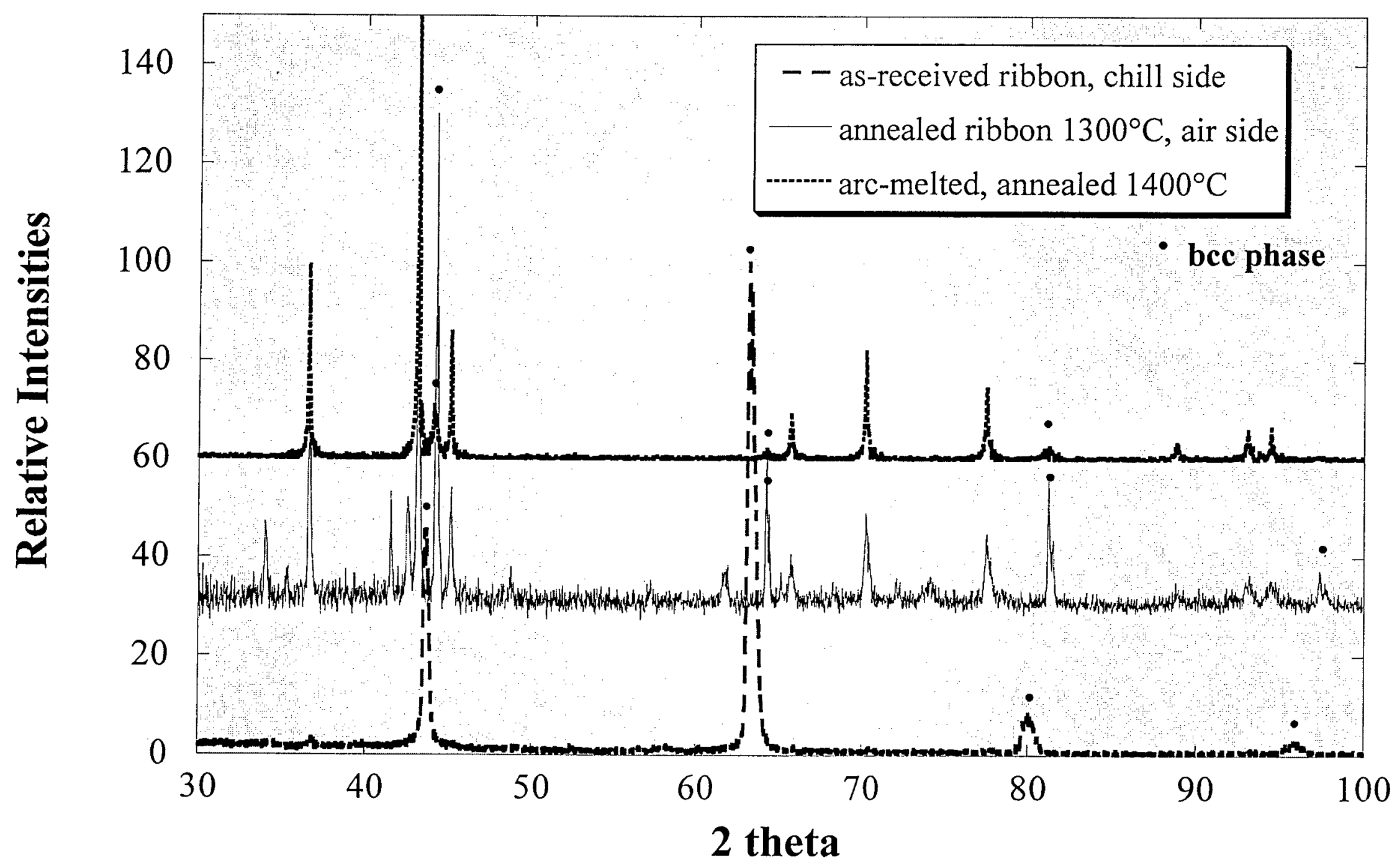

The annealed melt-spun ribbon shows decomposition of metastable bcc to bcc $+C 15$, and the arc-melted and annealed sample displays the equilibrium phases, $b c c+C 15$. 


\section{Lattice Constants of the $\mathrm{BCC}$ and $C 15$ Laves Phases and the $C 15$ Volume Percentage in Melt-Spun and Arc-Melted $\mathbf{C r N b}_{10} \mathbf{T i}_{10}$}

\begin{tabular}{|l|c|c|c|}
\hline Sample & $\mathbf{a}_{\text {bcc }}(\AA)$ & $\mathbf{a}_{C 15}(\AA)$ & $\mathbf{C 1 5} \mathbf{~ v o l \%}$ \\
\hline $\begin{array}{l}\text { melt-spun ribbon } \\
\text { chill side, as-received }\end{array}$ & $2.939 \pm 0.001$ & & - \\
\hline $\begin{array}{l}\text { melt-spun ribbon } \\
\text { air side, as-received }\end{array}$ & $2.924 \pm 0.001$ & $6.962 \pm 0.004$ & $25 \%$ \\
\hline $\begin{array}{l}\text { melt-spun ribbon } \\
\text { chill side, annealed } 1300^{\circ} \mathrm{C}\end{array}$ & $2.901 \pm 0.001$ & $6.963 \pm 0.001$ & $43 \%$ \\
\hline $\begin{array}{l}\text { melt-spun ribbon } \\
\text { air side, annealed } 1300^{\circ} \mathrm{C}\end{array}$ & $2.9034 \pm 0.0007$ & $6.966 \pm 0.002$ & $43 \%$ \\
\hline $\begin{array}{l}\text { arc-melted ingot } \\
\text { annealed } 1400^{\circ} \mathrm{C}\end{array}$ & $2.9031 \pm 0.0002$ & $6.9639 \pm 0.0004$ & $53 \%$ \\
\hline
\end{tabular}

* The as-received bcc lattice constant is beyond its terminal solid solution limits found in equilibrium conditions.

* The metastable bcc phase decomposes with annealing, and the bcc lattice constant decreases as the volume percentage of the $C 15$ phase increases. 


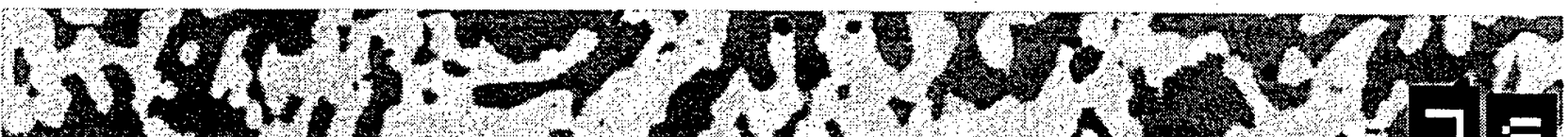

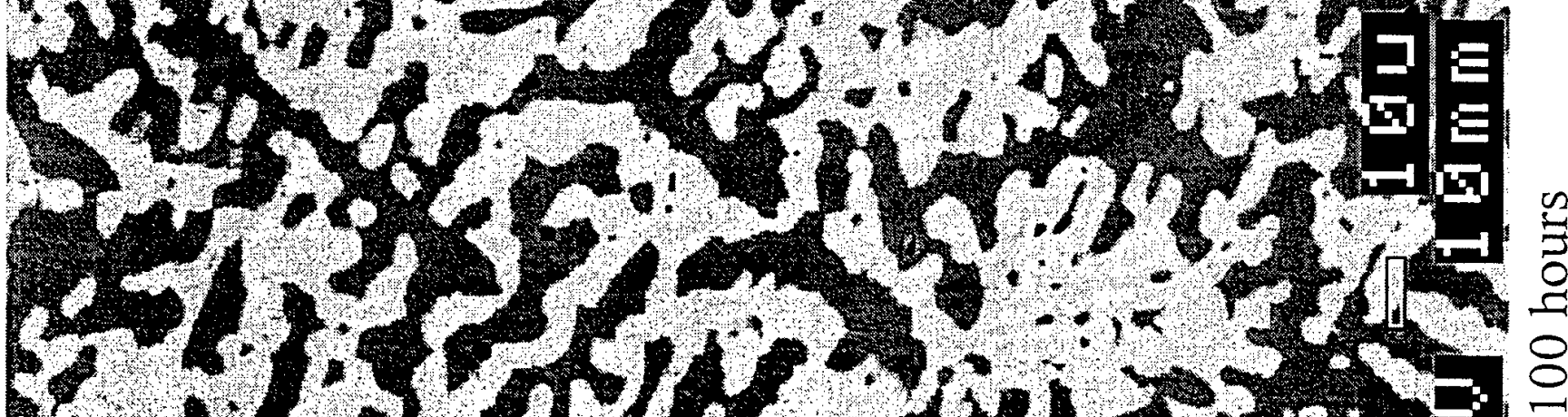

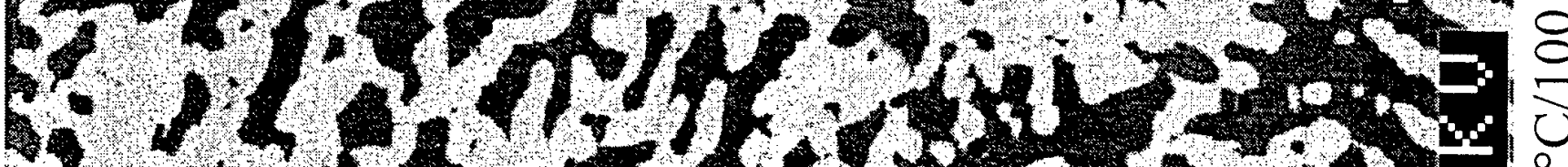

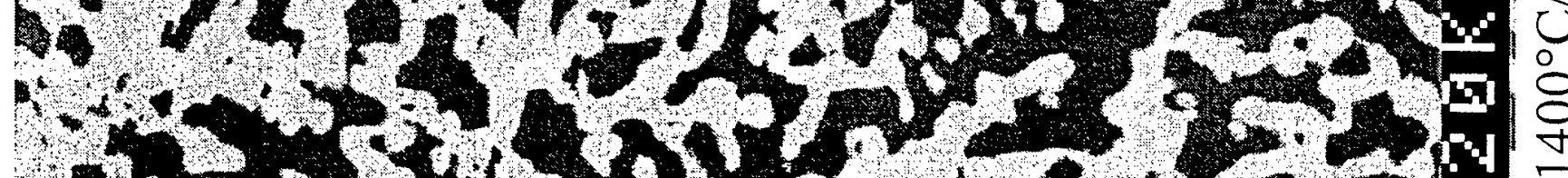

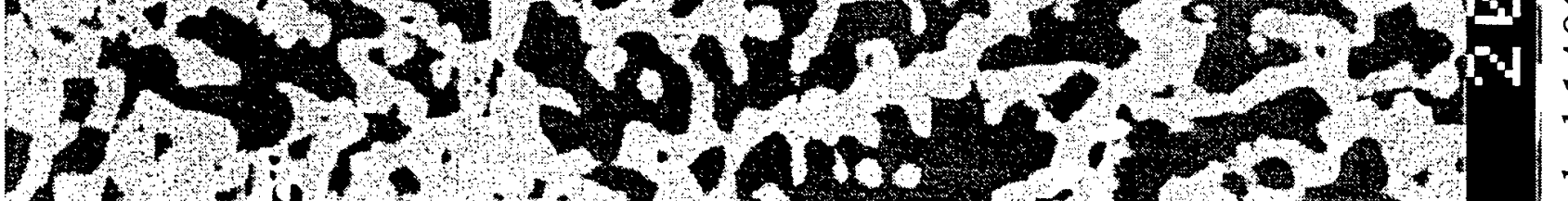

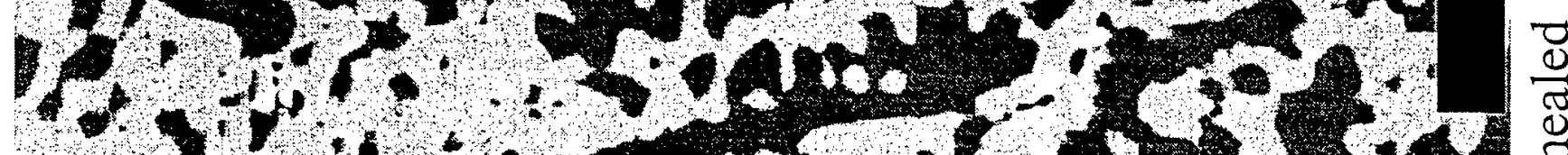

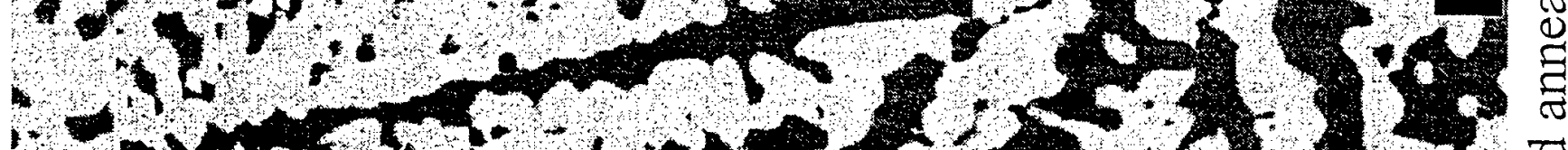

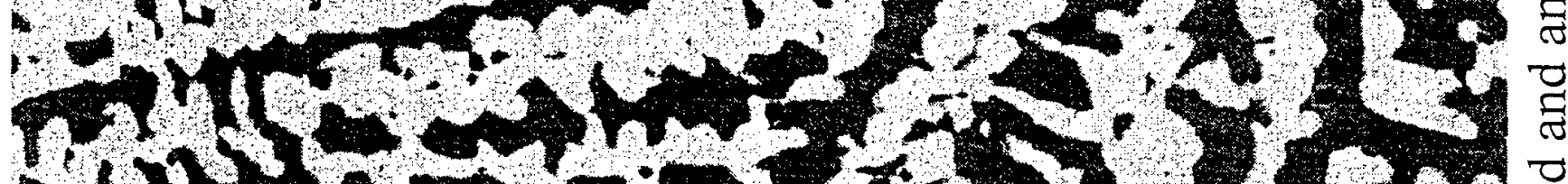

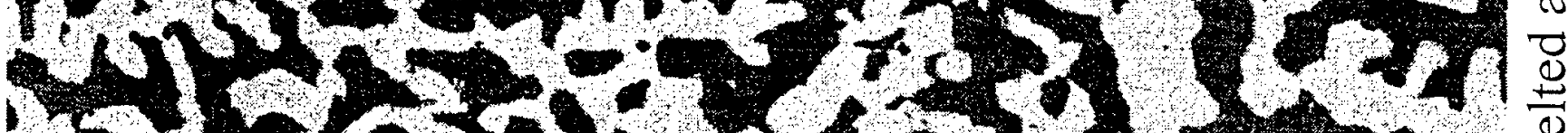

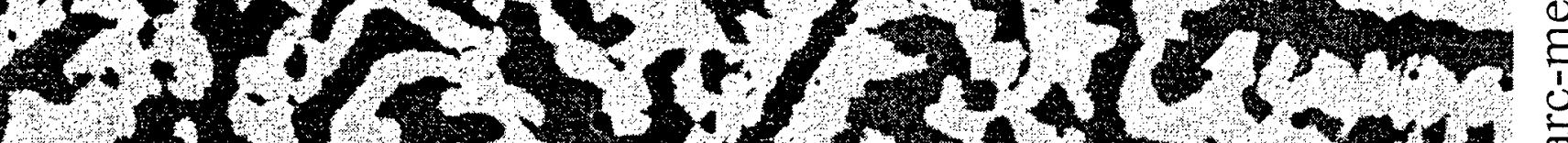

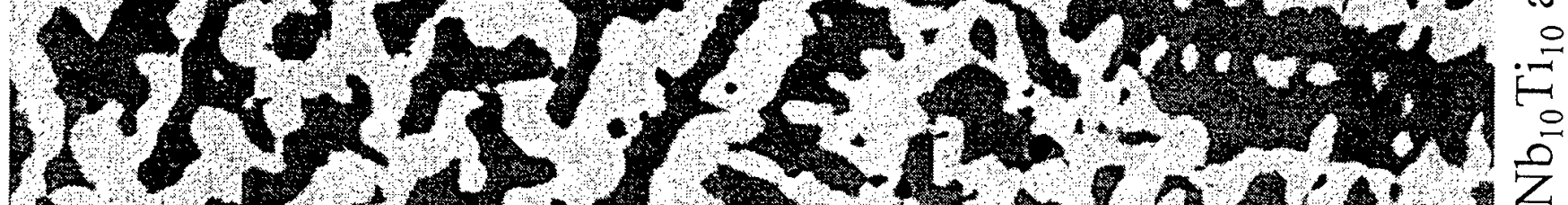

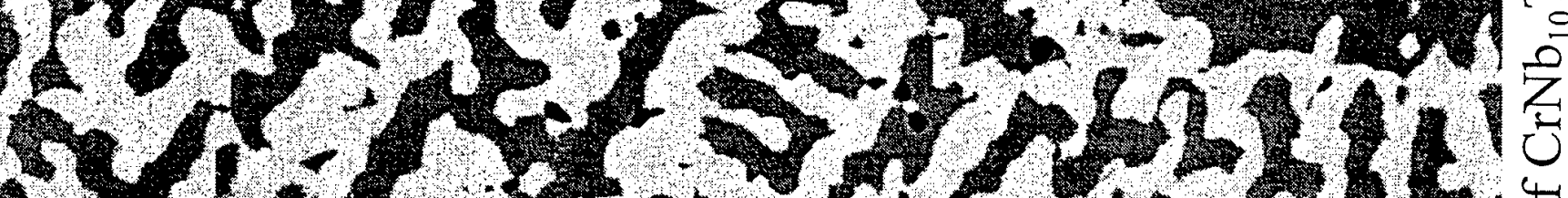

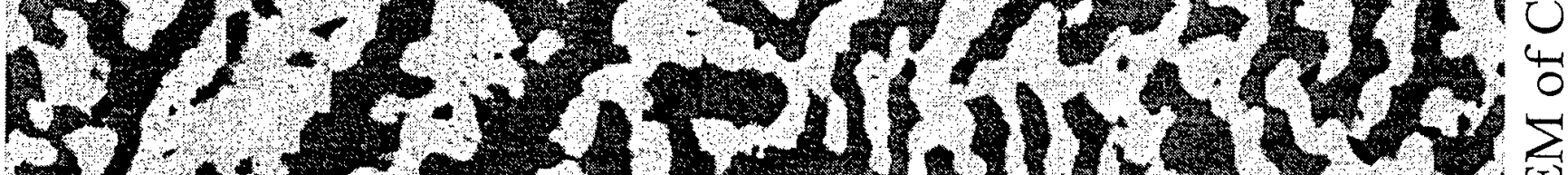

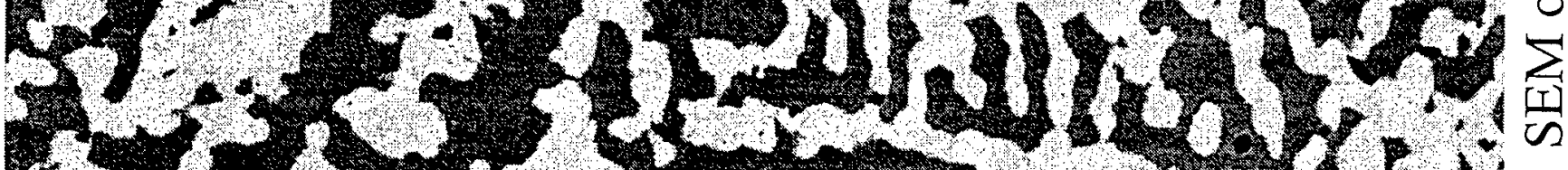

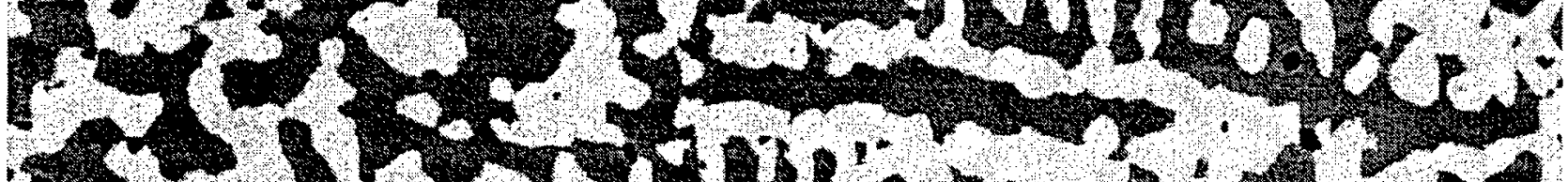

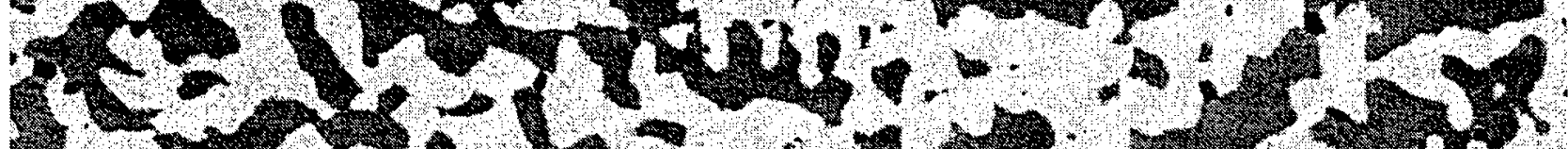

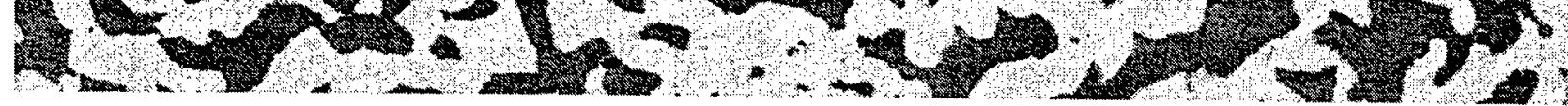




\section{Microstructural Development}

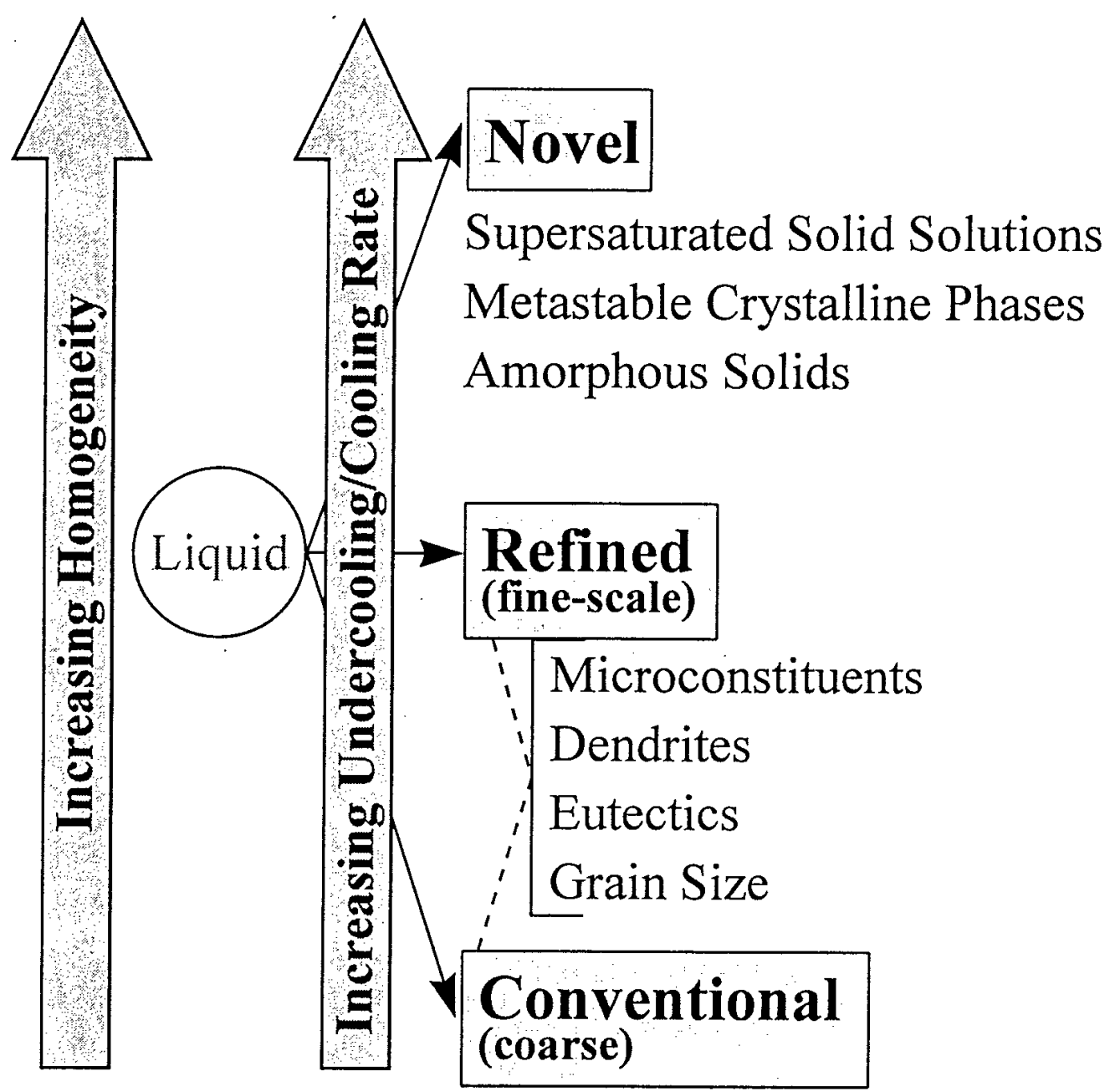

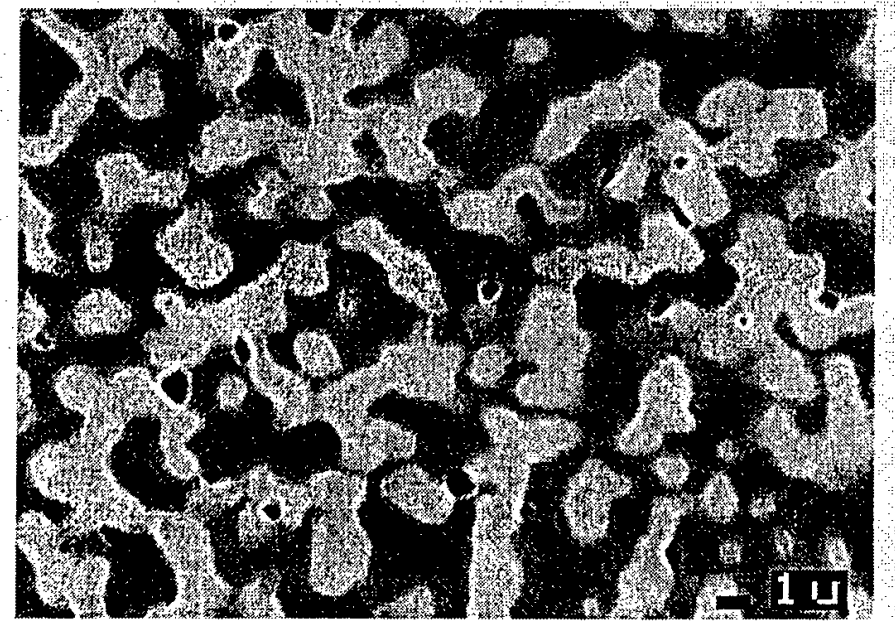

Decomposition of a Metastable Precursor

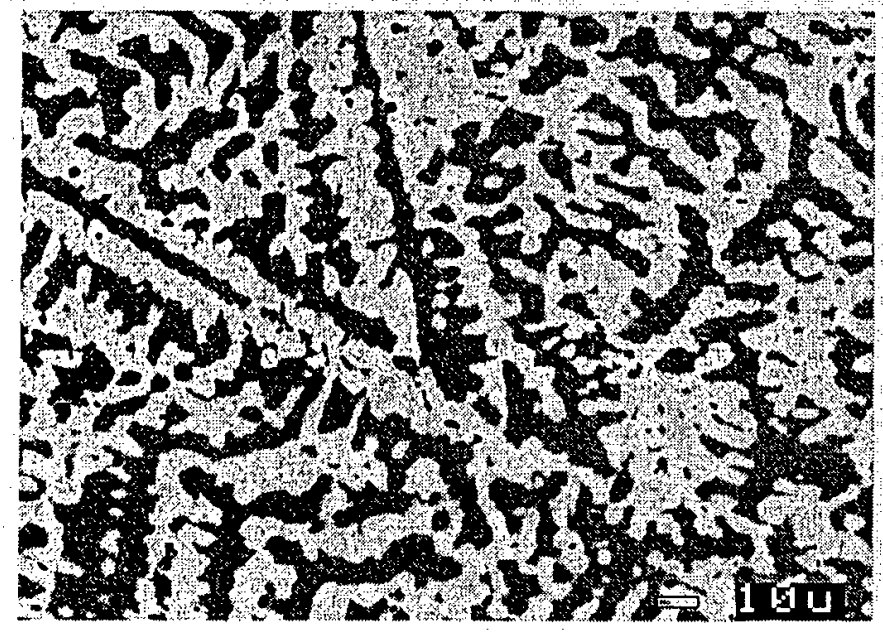

Arc-melted, annealed 


\section{Possible In-Situ Composite Formation Mechanisms}
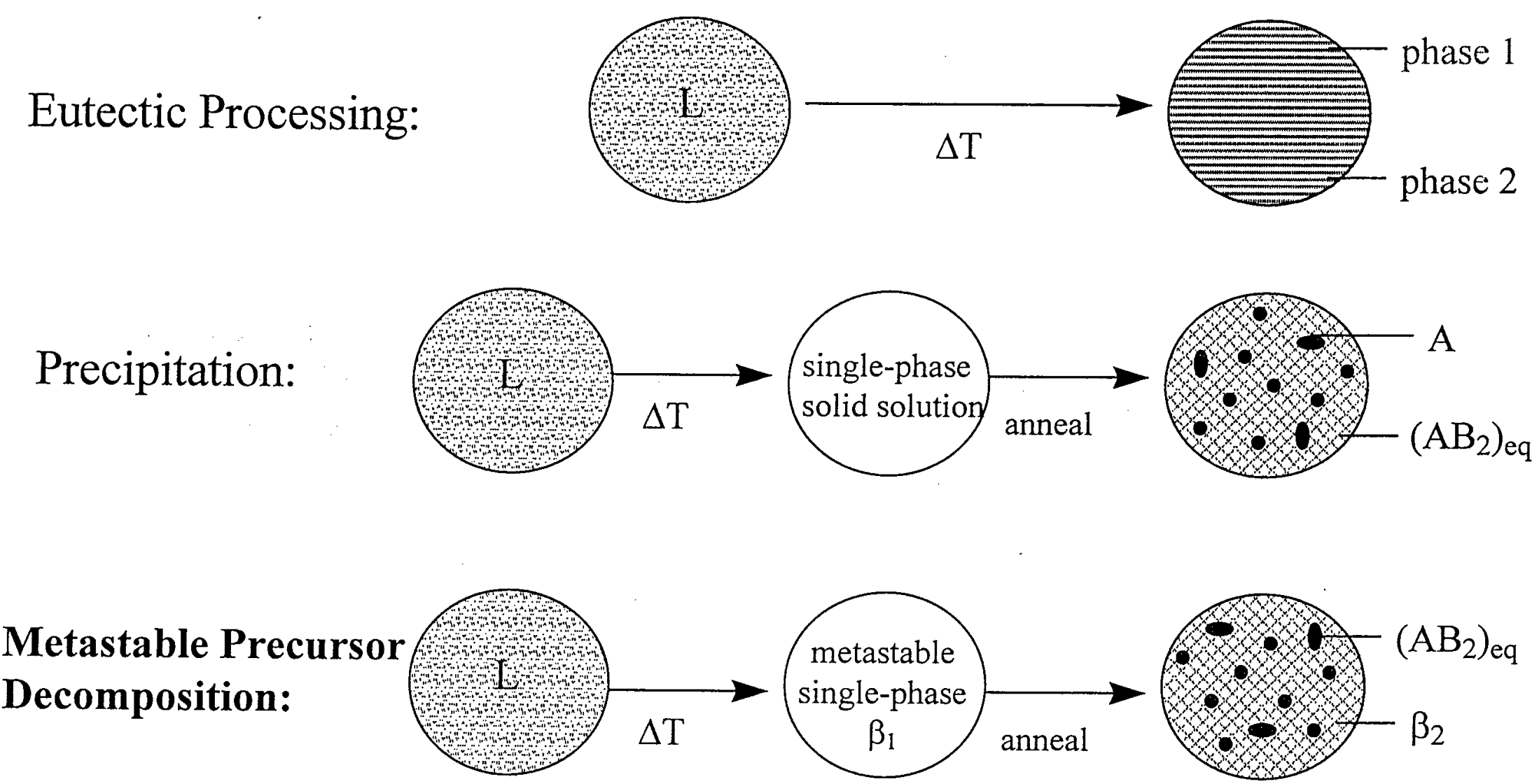

Decomposition of a supersaturated, metastable precursor can produce a very fine microstructure desired in two-phase alloys containing Laves phase intermetallics. 


\section{CONCLUSIONS}

1. Metastable bcc was achieved in a $\mathrm{CrNb}_{10} \mathrm{Ti}_{10}$ alloy via rapid solidification by a melt-spinning process. The bcc lattice constants $(2.939-2.924 \mathrm{~A})$ were outside the ranges for the equilibrium bcc phases in the $\mathrm{Nb}-\mathrm{Cr}$ - $\mathrm{Ti}$ system.

2. XRD, SEM, and TEM revealed that the chill-side of the as-received, melt-spun ribbons contained columnar grains of the metastable bcc phase. Small amounts of the C15 Laves phase appeared along the bcc grain boundaries, and as tiny, dispersed particles within the grains. The air-side had a dendritic structure.

3. Decomposition of the metastable bcc phase occurred during annealing at $1300^{\circ} \mathrm{C}$. A fine two-phase microstructure ( $\sim 1 \mu$ m length scale) of the equilibrium bcc phase and $C 15$ phase resulted.

4. The alloy composition processed with the conventional arc-melting method, followed by annealing, resulted in a coarse microstructure with remnants of a dendritic structure.

5. Using a metastable precursor, which then decomposes into the equilibrium phases, offers microstructural control and phase distributions not possible in conventional processing methods. Such a technique allows the optimization of microstructures and properties of Laves phase intermetallic alloys. 


\section{M98004386 \\ ||||||||||||||||||||||||||||||||||||||||||||||||||||||}

Report Number (14) $\frac{L A-4 R--97-5013}{\text { CONF }-971201-\cdots}$

Publ. Date (11) 199803

Sponsor Code (18) DOE/MA XF

UC Category (19) UC-904, DOE/ER 